\title{
The Role of Glutamate Receptor Redistribution in Locomotor Sensitization to Cocaine
}

\author{
Carrie R Ferrario, Xuan Li, Xiaoting Wang, Jeremy M Reimers, Jamie L Uejima and Marina E Wolf* \\ Department of Neuroscience, Rosalind Franklin University of Medicine and Science, North Chicago, IL, USA
}

\begin{abstract}
$\alpha$-Amino-3-hydroxy-5-methylisoxazole-4-propionate receptor (AMPAR) surface expression in the nucleus accumbens (NAc) is enhanced after withdrawal from repeated cocaine exposure. However, it is unclear whether this contributes to the expression of locomotor sensitization and whether similar changes can be observed in other striatal regions. In this study we examined the relationship between AMPAR surface expression in the NAc and locomotor sensitization. We also examined AMPAR distribution in the dorsolateral striatum (DS) and NMDA receptor (NMDAR) distribution in the NAc and DS. Trends but no significant changes in NMDAR distribution were found in the NAc after withdrawal. No NMDAR changes were observed in the DS. AMPAR surface expression was increased in the NAc 15 days after the last exposure to cocaine, but decreased in the DS. Re-exposure to cocaine on withdrawal day 14 decreased AMPAR surface expression in the NAc $24 \mathrm{~h}$, but not $30 \mathrm{~min}$, after challenge, but increased it in the DS $24 \mathrm{~h}$ and $30 \mathrm{~min}$ after challenge. Locomotor sensitization was evaluated at times associated with increased or decreased AMPAR surface expression in the NAc. The magnitude of sensitization did not vary with changes in the level of AMPAR surface expression, nor was it significantly reduced by decreasing AMPAR transmission through intra-NAc infusion of CNQX before cocaine challenge. On the basis of our results, and other findings, we suggest that the expression of sensitization has no clear relationship to altered AMPAR surface expression in the NAc, although the latter may have a role in the enhanced pursuit and self-administration of drugs observed in sensitized rats.

Neuropsychopharmacology (2010) 35, 818-833; doi: 10.1 038/npp.2009.190; published online 18 November 2009
\end{abstract}

Keywords: AMPA receptor; cocaine; dorsal striatum; NMDA receptor; nucleus accumbens; sensitization

\section{INTRODUCTION}

The nucleus accumbens (NAc) mediates motivated behaviors including drug seeking (Kelley, 2004). Glutamate inputs to NAc neurons that originate from limbic and cortical brain regions are critical for these behaviors (Groenewegen et al, 1999; Kelley, 2004). They excite NAc medium spiny neurons (MSNs) primarily through $\alpha$-amino3-hydroxy-5-methylisoxazole-4-propionate receptors (AMPAR; Pennartz et al, 1990; Hu and White, 1996). Thus, alterations in AMPAR surface expression following withdrawal from cocaine would be expected to influence the excitability of MSNs and drug-seeking behaviors mediated by the NAc.

In our earlier studies, we found increased surface expression of GluR1/2-containing AMPAR in the NAc of cocaine-sensitized rats after 7-21 days, but not 1 day, of withdrawal (Boudreau and Wolf, 2005; Boudreau et al, 2007; Boudreau et al, 2009). Similarly, GluR1 and GluR2 levels were increased in a synaptosomal membrane fraction

*Correspondence: Dr ME Wolf, Department of Neuroscience, Rosalind Franklin University of Medicine and Science, 3333 Green Bay Rd, North Chicago, IL 60064-3095, USA, Tel: + 847578 8659, Fax: + 847578 8515, E-mail: marina.wolf@rosalindfranklin.edu Received 30 June 2009; revised 12 October 2009; accepted 13 October 2009 prepared from the NAc of cocaine-sensitized rats on withdrawal day (WD) 21 but not WD1 (Ghasemzadeh et al, 2009), and electrophysiological studies demonstrated increased AMPA/NMDA ratios in MSN of the NAc shell after 10-14 days but not 1 day of withdrawal (Kourrich et al, 2007). Consistent with dysregulation of AMPAR transmission, cocaine sensitization is associated with alterations in LTP and LTD in the NAc (Yao et al, 2004; Goto and Grace, 2005; Moussawi et al, 2009). However, the relationship between enhanced AMPAR transmission and the expression of locomotor sensitization remains controversial. Some results suggest a causal relationship (Pierce et al, 1996; Bell et al, 2000). Yet, locomotor sensitization is present on WD1 when AMPAR surface levels are identical to those of drugnaive controls (Boudreau and Wolf, 2005). Other results suggest that AMPAR internalization, rather than enhanced surface expression, underlies expression of locomotor sensitization (Brebner et al, 2005; see also Bachtell et al, 2008).

Our goal was to further explore the relationship between AMPAR surface expression and the expression of locomotor sensitization, and to extend our earlier findings to include NMDA receptor (NMDAR) distribution and analysis of the dorsolateral striatum (DS). Our earlier studies used a regimen that produced locomotor sensitization in about half of cocaine-treated rats, and only rats developing 
sensitization exhibited increased AMPAR surface expression (Boudreau and Wolf, 2005; Boudreau et al, 2007). In this study, we used a regimen that consistently produces sensitization in all cocaine-pretreated rats (Li et al, 2004). We measured locomotor activity and AMPAR surface expression in saline controls and cocaine-sensitized rats after withdrawal and at different times after cocaine or saline challenge. Although it is clear that the NAc is important for the expression of behavioral sensitization (Pierce and Kalivas, 1997; Vanderschuren and Kaliavs 2000; Koya et al, 2009) and that AMPAR are the main driving force for activation of MSN (above), our results suggest that changes in AMPAR surface expression are not directly linked to the expression of locomotor sensitization to cocaine. This conclusion is also supported by behavioral findings (Bachtell and Self, 2008). Instead, we suggest that increased AMPAR surface expression in the NAc may contribute to the enhanced pursuit and self-administration of drugs observed in sensitized rats (Vezina, 2004). This hypothesis is supported by evidence linking enhanced AMPAR transmission in the NAc of stimulant-treated rats to enhanced drug craving and relapse (Suto et al, 2004; Conrad et al, 2008; Anderson et al, 2008).

\section{MATERIALS AND METHODS}

\section{Subjects and Sensitization}

Male Sprague-Dawley rats (Harlan; 250-275 g) were housed in groups of three (12:12 light/dark). Food and water were continually available. All treatments and testing were conducted in the light phase of the cycle and were approved by the Institutional Animal Care and Use Committee. After acclimatization to the colony (7 days), rats were injected (i.p.) with either saline $(0.9 \%, 1 \mathrm{ml} / \mathrm{kg})$ or cocaine hydrochloride $(15 \mathrm{mg} / \mathrm{kg}$, weight of salt; Sigma-Aldrich, St Louis, MO) once per day on 8 consecutive days. On each pretreatment day, each rat was placed in a rectangular plastic cage $(41 \times 25.5 \times 2.3 \mathrm{~cm})$ surrounded by a photocell frame (San Diego Instruments, San Diego, CA). Locomotion was recorded as the total number of beam breaks per $5 \mathrm{~min}$. After $40 \mathrm{~min}$, rats were injected with saline or cocaine. Locomotion was recorded throughout the habituation period and $1.5 \mathrm{~h}$ after injection.

\section{Experiment 1: Receptor Distribution after Withdrawal from Repeated Cocaine or Saline Exposure}

Fifteen days after the last pretreatment injection (WD15), the NAc (core and shell) and a portion of DS were removed and crosslinked with bis(sulfosuccinimidyl)suberate $\left(\mathrm{BS}^{3}\right.$; Pierce Biotechnology, Rockford, IL) as described below (Sal, $N=10$; Coc, $N=12$ ).

\section{Experiment 2: Receptor Distribution $24 \mathrm{~h}$ or 30 Min after Cocaine Challenge}

Additional rats were pretreated as described above (Sal, $N=21$; Coc, $N=24$ ) and challenged on WD14 with i.p. saline $(0.9 \%, 1 \mathrm{ml} / \mathrm{kg})$ or cocaine $(15 \mathrm{mg} / \mathrm{kg})$. This produced four groups: saline-pretreated challenged with saline (Sal-Sal, $N=9$ ), saline-pretreated challenged with cocaine
(Sal-Coc, $N=12$ ), cocaine-pretreated challenged with saline (Coc-Sal, $N=12$ ), and cocaine-pretreated challenged with cocaine (Coc-Coc, $N=12$ ). Locomotion was recorded throughout the challenge session. Twenty-four hours after the challenge, bilateral NAc and DS tissue was crosslinked with $\mathrm{BS}^{3}$ as described below. Thus, 'challenge' animals were killed on the same day after pretreatment as the 'withdrawal' group in Experiment 1, but were re-exposed to cocaine or saline and the activity monitors $24 \mathrm{~h}$ before tissue collection. To assess rapid effects of cocaine, another group was pretreated with cocaine $(N=27)$. Some of these rats remained in the colony for 14 days, whereas others received a challenge of cocaine or saline on WD14. Rats were killed 30 min after the challenge, and NAc tissue was crosslinked with $\mathrm{BS}^{3}$ (Coc-WD14 $N=9$, Coc-Sal/30 $\min N=9$, Coc-Coc/ $30 \min N=9$ ).

\section{Experiment 3: Do Decreases in AMPAR Surface Expression or Transmission Affect the Expression of Locomotor Sensitization?}

Experiment 2 showed that AMPAR surface expression is decreased $24 \mathrm{~h}$ after cocaine challenge. To determine whether this decrease affects the expression of locomotor sensitization, additional rats were pretreated with cocaine $(N=12)$. On WD14, rats were challenged with cocaine $(15 \mathrm{mg} / \mathrm{kg})$ and then given a second challenge $24 \mathrm{~h}$ later (WD15). Locomotion was measured as described above. As another approach to determining whether decreased AMPAR transmission in the NAc affects the expression of locomotor sensitization, cocaine-pretreated rats were given an intra-NAc infusion of the AMPAR antagonist CNQX (Sigma-Aldrich) or vehicle (saline) before cocaine or saline challenge. Guide cannulae (23-gauge; Plastics One, Roanoke, VA) were implanted bilaterally $1.5 \mathrm{~mm}$ above the NAc, aimed at the core (coordinates from Bregma: $6^{\circ}$ medial angle; AP: +1.4 , ML: \pm 2.5 , DV: -5.5$)$. After recovery, rats were pretreated with cocaine $(N=43)$. Fourteen days later, rats were given a bilateral intra-NAc infusion of CNQX $(0.03 \mu \mathrm{g} / 0.5 \mu \mathrm{l}$ or $0.3 \mu \mathrm{g} / 0.5 \mu \mathrm{l})$ or vehicle $(0.5 \mu \mathrm{l} / \mathrm{side})$. Infusions occurred over $2 \mathrm{~min}$; the injector was withdrawn $1 \mathrm{~min}$ later. Rats received a cocaine $(15 \mathrm{mg} / \mathrm{kg}$, i.p.) or saline $(0.9 \%, 1 \mathrm{ml} / \mathrm{kg}$ i.p. $)$ challenge injection $10 \mathrm{~min}$ after the intracranial infusion. This resulted in six groups: $0.03 \mu \mathrm{g}$ CNQX-Coc, $0.03 \mu \mathrm{g}$ CNQX-Sal, $0.3 \mu \mathrm{g}$ CNQX-Coc, $0.3 \mu \mathrm{g}$ CNQX-Sal, Veh-Coc, and Veh-Sal ( $N=5-10 /$ group; see Results section). The doses of CNQX used here are equivalent to those used in Pierce et al (1996) and Bell et al (2000). Cannulae placements were confirmed in coronal sections stained with Cresyl violet (ICN Biomedicals, Aurora, $\mathrm{OH})$.

\section{Experiment 4: Does Cocaine Challenge Produce a Transient or Long-Lasting Decrease in AMPAR Surface Expression?}

Results from Experiments 1 and 2 showed that although repeated cocaine increased AMPAR surface expression in the NAc after withdrawal, AMPAR surface expression is decreased $24 \mathrm{~h}$ after cocaine challenge. To determine whether this decrease is transient or long lasting, another group of animals was pretreated with cocaine $(N=28)$. 
Fourteen days later, half the rats were challenged with cocaine as described in Experiment 2 (Coc-Coc/WD21, $N=13$ ), whereas the other half were undisturbed (Cocl WD21, $N=15$ ). After 7 more days, NAc tissue was crosslinked as described below. Thus, for the Coc-Coc/ WD21 group, tissue was collected 21 days after the last cocaine-pretreatment injection, but 7 days after cocaine challenge.

\section{Protein Crosslinking Using $\mathrm{BS}^{3}$}

Cell surface and intracellular protein levels were determined using a protein crosslinking assay (Boudreau and Wolf, 2005). This assay uses $\mathrm{BS}^{3}$, a bi-functional chemical crosslinker that does not penetrate cell membranes and therefore crosslinks cell surface proteins into high molecular weight aggregates, whereas intracellular proteins are unmodified. Surface and intracellular glutamate receptor pools can then be separated based on molecular weight using SDS-PAGE and quantified by immunoblotting. The band corresponding to crosslinked AMPAR subunits is $\sim 400$ to $600 \mathrm{kDa}$, consistent with crosslinking of subunits within one tetrameric AMPAR (four subunits of $\sim 100 \mathrm{kDa}$ plus two or four small $(\sim 40 \mathrm{kDa})$ transmembrane AMPA receptor regulatory proteins). The length of the $\mathrm{BS}^{3}$ spacer arm (11 angstroms) is also consistent with crosslinking within a tetrameric AMPAR (Safferling et al, 2001). It should be noted that although $\mathrm{BS}^{3}$ provides an accurate measure of relative differences in surface to intracellular protein (S/I) ratios between experimental groups, the absolute level of $S / I$ that is measured depends on the experimental conditions. For example, consider two proteins, $\mathrm{X}$ and $\mathrm{Y}$, that are similarly distributed between $\mathrm{S}$ and $\mathrm{I}$ compartments. If antibody to $\mathrm{X}$ recognizes its crosslinked form less avidly than the unmodified (intracellular) form, whereas antibody to $\mathrm{Y}$ recognizes both forms equally well, the measured S/I ratio will be lower for X than Y, even though the proportion of each protein on the surface is actually the same. Finally, it should be noted that a change in surface expression of an AMPAR subunit can be taken to indicate a change in AMPAR receptor surface expression, because tetramerization of AMPAR subunits (forming a functional receptor) is one of the requirements for exit from the endoplasmic reticulum (Greger and Esteban, 2007).

For each rat, NAc and DS were rapidly dissected from a $2 \mathrm{~mm}$ coronal section and chopped into $400 \mu \mathrm{m}$ slices using a McIllwain chopper (The Vibratome, St Louis, MO). Tissue was incubated with artificial cerebrospinal fluid containing $2 \mathrm{mM} \mathrm{BS}^{3}$ for $15 \mathrm{~min}$ (Experiments 1 and 2) or $30 \mathrm{~min}$ (Experiment 3) at $4^{\circ} \mathrm{C}$ with gentle agitation. Extensive methodological studies (AC Boudreau et al, in preparation) have established that $15-30 \mathrm{~min}$ of crosslinking is optimal for the detection of AMPAR subunit surface expression. We used the longer time ( $30 \mathrm{~min}$ ) for Experiment 3 to improve our ability to detect the crosslinked species for GluR2. Comparisons were only made between groups that had identical crosslinking duration. Crosslinking was terminated with glycine $(100 \mathrm{mM} ; 10 \mathrm{~min})$. Slices were resuspended in $400 \mu \mathrm{l}$ (NAc) or $200 \mu \mathrm{l}$ (DS) of lysis buffer $(25 \mathrm{mM}$ HEPES; pH 7.4, $500 \mathrm{mM} \mathrm{NaCl}, 2 \mathrm{mM}$ EDTA, $1 \mathrm{mM}$ DTT, $1 \mathrm{mM}$ phenylmethyl sulfonyl fluoride, $20 \mathrm{mM} \mathrm{NaF}, 1: 100$ protease inhibitor cocktail set I (Calbiochem, San Diego,
CA), and $0.1 \%$ Nonidet P-40 (v/v)). Samples were sonicated and centrifuged. The supernatant was aliquotted and stored at $-80^{\circ} \mathrm{C}$. Protein concentration was determined using the BioRad protein assay kit (BioRad, Hercules, CA).

\section{SDS-PAGE and Immunoblotting}

$\mathrm{BS}^{3}$ crosslinked samples were heated $\left(70^{\circ} \mathrm{C}, 10 \mathrm{~min}\right)$ in Laemmli sample treatment buffer with $5 \% \beta$-mercaptoethanol, loaded (20 $\mu \mathrm{g}$ protein) and electrophoresed on $4-15 \%$ Bis-Tris gradient gels (BioRad) under reducing conditions. Proteins were transferred onto PVDF membranes (Amersham Biosciences, Piscataway, NJ) using constant current $(1.15 \mathrm{~mA})$ for $1.5 \mathrm{~h}$. Complete transfer of high molecular weight aggregates was confirmed by staining gels after transfer with Coomassie blue. A cooling coil was used throughout the transfer to prevent excessive heating. After transfer, membranes were rinsed in $\mathrm{ddH}_{2} \mathrm{O}$, blocked for $1 \mathrm{~h}$ at room temperature with $1 \%(\mathrm{v} / \mathrm{v})$ goat serum and $5 \%$ $(\mathrm{w} / \mathrm{v})$ nonfat dry milk or $3 \%(\mathrm{w} / \mathrm{v})$ bovine serum albumin in TBS-Tween 20 (TBS-T; $0.05 \%$ Tween 20, v/v), and then incubated (in $1 \times$ TBS) overnight on a rocker $\left(4^{\circ} \mathrm{C}\right)$ with primary antibodies: GluR1, 1:1000 (Millipore, Billerica, MA; AB1504); GluR2, 1:1000 (in block, Millipore; AB1768); GluR2/3, 1:2000 (Millipore; AB1506); NR2B, 1:1000 (Calbiochem; 454582); NR2A/B, 1:2500 (Millipore; $\mathrm{AB} 1548 \mathrm{~W})$. Membranes were washed in TBS-T, incubated at RT for $60 \mathrm{~min}$ with HRP-conjugated anti-rabbit or mouse IgG ( $1: 10$ 000; Invitrogen, Carlsbad, CA), washed with TBS-T, and rinsed with $\mathrm{ddH}_{2} \mathrm{O}$. Membranes were immersed in chemiluminescence (ECL) detecting substrate (GE Healthcare, Piscataway, NJ) and images acquired with a VersaDoc 5000 imaging system (BioRad). Membranes were washed in $\mathrm{ddH}_{2} \mathrm{O}$ followed by TBS-T solution and stained with Ponceau S (5 min, Sigma-Aldrich) to assess total protein in the lane. For some proteins, technical problems prevented quantification of one or two lanes. Therefore, the $N$ reported for biochemical studies is sometimes different than the number of rats treated.

\section{Data Analysis}

Behavioral data were evaluated using two-way repeated measures ANOVA with time $\times$ pretreatment group, time $\times$ challenge, or time $\times$ injection as factors. For western blotting, immunoreactivity was quantified using Quantity One analysis software (BioRad). A background value was obtained and diffuse densities for surface and intracellular bands in each lane were determined. Total protein levels were determined by summing surface and intracellular values. Surface, intracellular, and total protein values were then normalized to total protein in the lane as determined by Ponceau $S$ staining. This method of correction was selected, rather than normalizing to a single protein, because proteins used as loading controls may be affected by repeated drug exposure. Corrected values for surface, intracellular, and total protein levels, as well as the ratio of S/I, were determined for each rat. Groups were compared using two-way ANOVA followed by Bonferroni post hoc tests, or unpaired $t$-tests when appropriate. $N$ corresponds to the number of rats in each group. 


\section{RESULTS}

Experiment 1. Receptor Distribution after Withdrawal from Repeated Cocaine or Saline Exposure

Rats received either saline or cocaine injections on 8 consecutive days; all injections were given in an activity monitor. Figure 1 compares the locomotor activity of saline and cocaine groups during the first and last pretreatment sessions (Sal $N=10$, Coc $N=12$ ). Locomotor activity during the $40 \mathrm{~min}$ habituation period did not differ between saline- and cocaine-pretreated groups during either the first or last pretreatment session (Figures $1 \mathrm{a}$ and $\mathrm{b}$; the same is true for all subsequent experiments), indicating that a conditioned locomotor response to the testing environment did not develop in the cocaine-pretreated group. The locomotor response to saline injection did not differ between the first and last pretreatment sessions (Figures $1 \mathrm{a}$ and $\mathrm{b}$; open circles). Repeated cocaine injections produced locomotor sensitization as indicated by a significantly greater locomotor response to the last injection of cocaine compared with the first (Figures $1 \mathrm{a}$ and $\mathrm{b}$, closed squares; main effect of injection, $\mathrm{F}_{(1,242)}=5.2, p=0.03$; injection $\times$ time interaction, $\left.\mathrm{F}_{(11,242)}=5.3, p<0.001\right)$.

On WD15, rats were killed, the NAc and DS were removed, and tissue slices were incubated with the membrane impermeant protein crosslinking reagent $\mathrm{BS}^{3}$. We selected WD15 because it is a time when locomotor sensitization produced by our regimen is robust (Experiment 2 and Li et al, 2004) and when increased AMPAR surface expression occurs after a different sensitization regimen (Boudreau and Wolf, 2005; Boudreau et al, 2007). Figure 2 shows the distribution of AMPAR subunits in NAc on WD15. When compared with saline-pretreated controls, the ratio of surface-expressed GluR1 to intracellular GluR1 (GluR1 surface/intracellular ratio, or S/I) was significantly increased in the cocaine-pretreated group (Figure 2a; $\mathrm{t}_{16}=2.44, p<0.05 ;$ Sal $N=8$, Coc $\left.N=10\right)$. The GluR2 S/I ratio was also significantly increased (Figure $2 b ; t_{19}=2.09$, $p<0.05$; Sal $N=9$, Coc $N=12$ ), whereas a trend toward an increased S/I ratio was detected using an antibody that recognizes both GluR2 and GluR3 subunits (GluR2/3, Figure 2c; Sal $N=9$, Coc $N=12$ ). Unfortunately, we cannot measure GluR3 surface expression directly because currently available GluR3 antibodies do not recognize GluR3 after crosslinking. These results are consistent with increased surface expression of GluR1/2-containing AMPAR.

In contrast to NAc, the distributions of GluR1 and GluR2 in DS were not significantly altered on WD15 after repeated cocaine exposure (Figure 3a: Sal $N=8$, Coc $N=11$; Figure 3b: Sal $N=10$, $\operatorname{Coc} N=12$ ), whereas GluR2/3 total protein and surface levels were significantly decreased (Figure 3c; total protein, $\mathrm{t}_{19}=2.29, p<0.05$; surface protein, $\mathrm{t}_{19}=2.11, p<0.05 ;$ Sal $N=9$, Coc $N=12$ ). These results suggest a decrease in GluR3-containing AMPAR. Some of these may be GluR1/3, because we observed a small although nonsignificant decrease in the GluR1 S/I ratio in the cocaine rats (Figure 3a). Quantitative coimmunoprecipitation data indicate that most AMPAR in both NAc and DS are GluR1/2 or GluR2/3, whereas the remaining receptors $(<10 \%)$ are GluR2-lacking AMPAR (Reimers et al, 2007; Boudreau et al, 2007; Conrad et al, 2008), although it should be noted that coimmunoprecipitation assesses total cellular receptors and cannot specifically determine synaptic AMPAR composition (see Lu et al, 2009). Within the category of GluR2-lacking AMPAR, we have confirmed the existence of homomeric GluR1 and GluR1/3 receptors, but could not determine whether homomeric GluR3 was also present. Therefore, we cannot rule out a contribution of homomeric GluR3 to results shown in Figure 3. However, in evaluating this experiment and other experiments described in subsequent sections, it

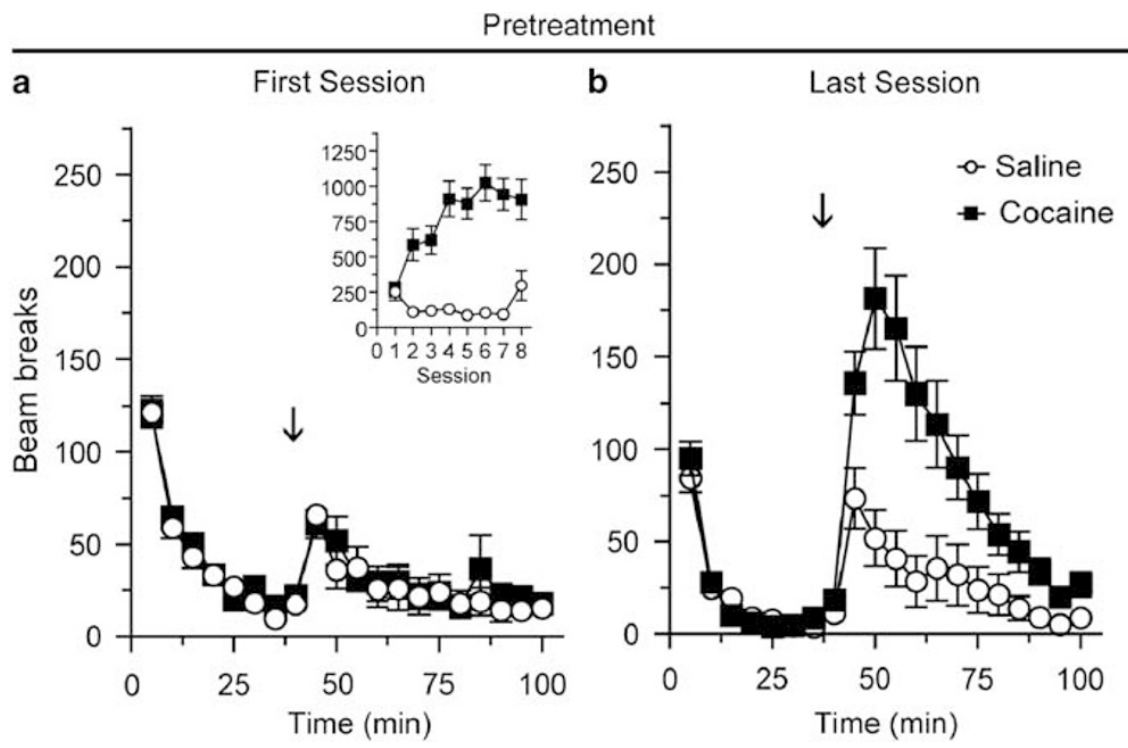

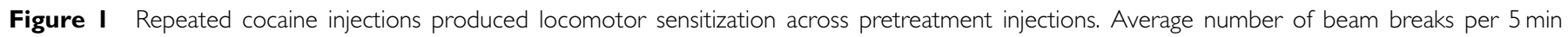

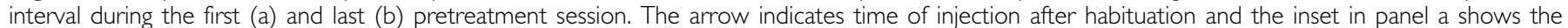

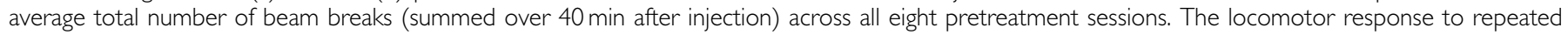

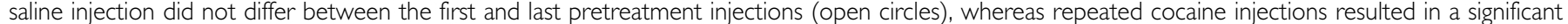
increase in locomotor activity in response to the last vs first injection of cocaine (closed squares). Sal $N=10, \mathrm{Coc} N=12$. 
a

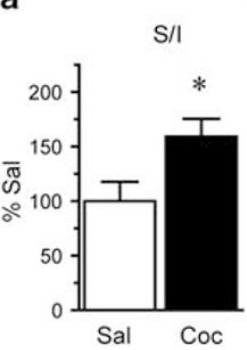

Surface

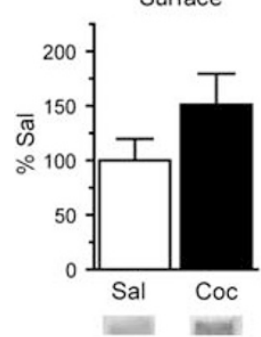

GluR1 NAc

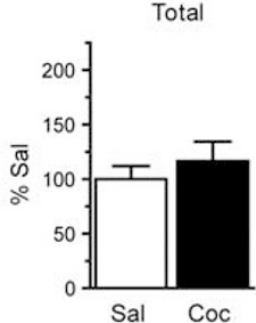

Intracellular

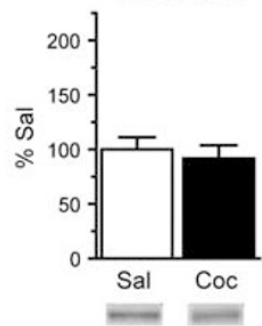

b
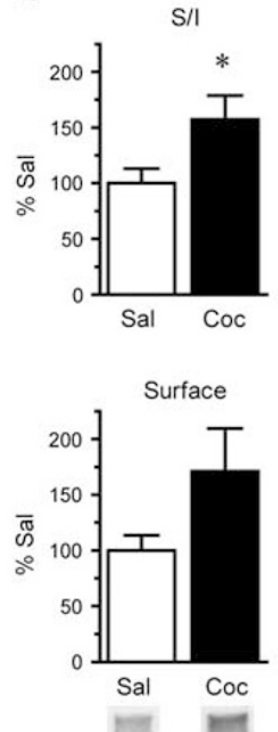

GluR2 NAC
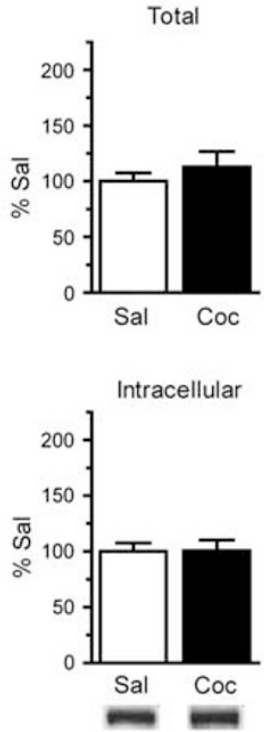

c

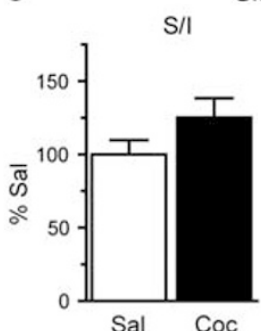

GluR2/3 NAc
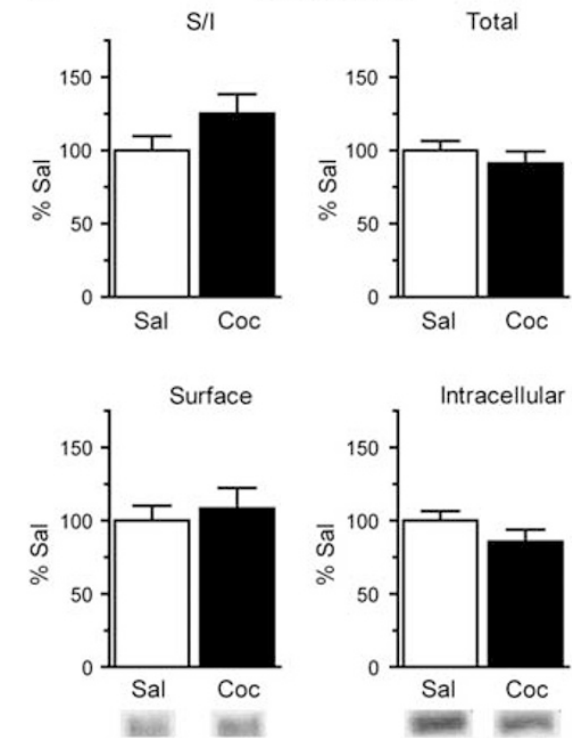

Figure 2 Surface expression of GluRI and GluR2 in the NAc is increased after I 5 days of withdrawal from repeated cocaine injections. Data are expressed as average percent change from saline controls detected with antibodies to GluRI (a; Sal $N=8, \operatorname{Coc} N=\mid 0$ ), GluR2 (b; Sal $N=9$, Coc $N=\mid 2$ ), and GluR2/3 (c; Sal N=10, $\operatorname{Coc} N=12$ ). Surface/intracellular ratios $(S / I)$ for GluRI and GluR2 were significantly increased in cocaine-pretreated rats $(* p<0.05)$. Representative bands are shown at the bottom of each panel. Please note that panel $c$ has a different $x$ axis scale than panels a and $b$.

a
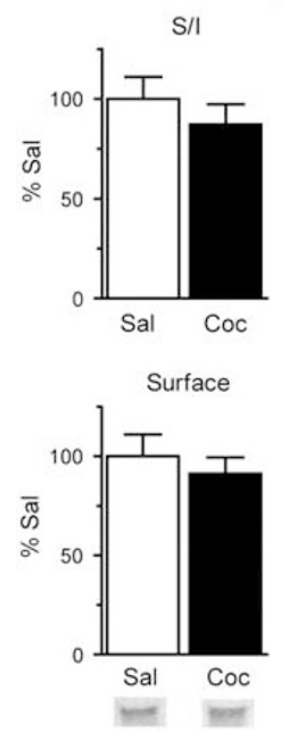

GluR1 DS
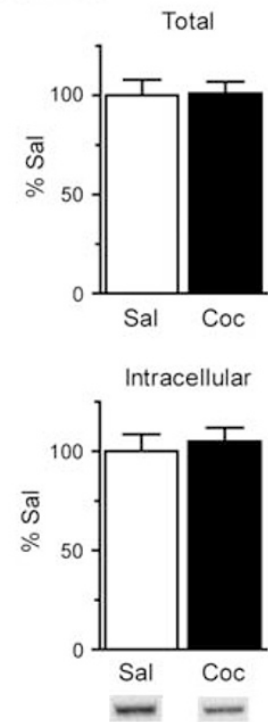

b
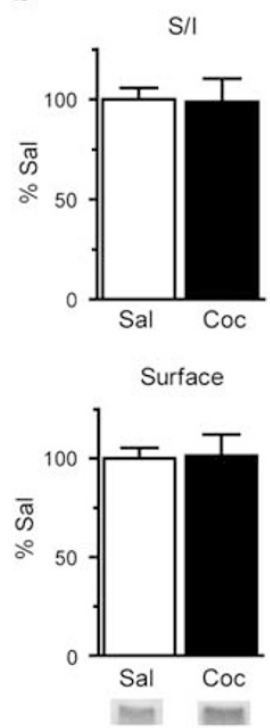

GluR2 DS
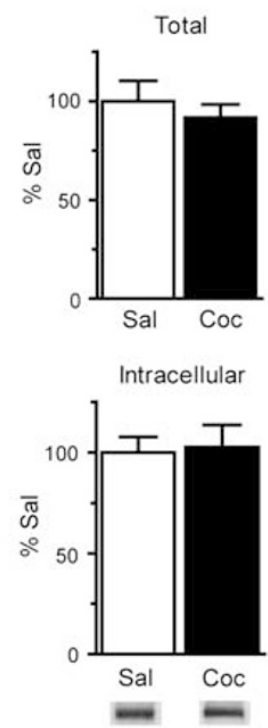

C<smiles>[SiH3]</smiles>

GluR2/3 DS
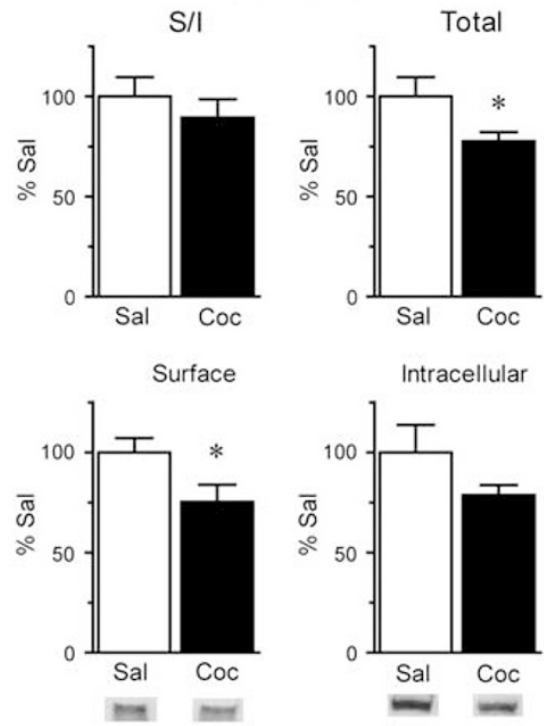

Figure 3 AMPAR surface expression in the DS, detected with GluR2/3 antibody, is decreased after 15 days of withdrawal from repeated cocaine injections. Data are expressed as average percent change from saline controls for GluRI (a; Sal $N=8, \operatorname{Coc} N=1 \mathrm{I}$ ), GluR2 (b; Sal N= I0, Coc $N=\mid 2$ ), and GluR2/3 (c; Sal N=9, $\operatorname{Coc} N=12$ ). In contrast to the NAc (Figure 2), GluRI, and GluR2 distribution in the DS were not significantly altered, whereas GluR2/3 surface and total levels were significantly decreased $(* p<0.05)$. Representative bands are shown at the bottom of each panel.

is important to recognize that the magnitude of changes detected for two different subunits cannot be directly compared. One reason is that primary antibodies may differ in their ability to recognize their target proteins, particularly after crosslinking (see Materials and methods section for more discussion). Differences in absolute levels of AMPAR subunits are also important. For example, in evaluating the data in Figure 3, an important consideration is that the NAc contains substantially more GluR 1 than GluR3, so a modest change in the percent of GluR1 on the surface could indicate redistribution of the same absolute number of receptors as a more marked change in surface GluR3. These issues, along with the inability to measure GluR3 directly, make it difficult to infer subunit composition from our results.

Given that this cocaine sensitization regimen increases dendritic spine density in the NAc (Li et al, 2004) and that NMDAR are generally present at new synapses before AMPAR are added (Constantine-Paton and Cline, 1998), it follows that if new synapses were made, then NMDAR 
surface expression would be increased. Therefore, we evaluated NMDAR subunit distribution in the NAc after 15 days of withdrawal from repeated cocaine or saline exposure. We used an NR2B-selective antibody and an antibody that recognizes both NR2A and NR2B (NR2A/B). Currently available lots of NR2A and NR1 antibodies do not recognize these proteins after crosslinking. No significant differences were found between cocaine- and salinepretreated groups for NR2B or NR2A/B, although trends toward increased surface, intracellular, and total NR2A/B levels were observed (Supplementary Figure 1a and b; Sal $N=10, \operatorname{Coc} N=12$ ). In the absence of changes in NR2B, the trends observed with the NR2A/B antibody may indicate increased expression of NR2A in the sensitized rats (see Discussion section). We also examined NR2A/B immunoreactivity in DS, where enhanced dendritic spine density has also been observed (Jedynak et al, 2007). No significant differences were found between cocaine- and salinepretreated groups after 15 days of withdrawal (Supplementary Figure 1c; Sal $N=10$, Coc $N=12$ ). Although NMDARs can be difficult to solubilize from adult brain tissue (see Al-Hallaq et al, 2007 for discussion), control studies indicated that we are recovering $75-85 \%$ of NMDAR and AMPAR in our $\mathrm{BS}^{3}$ crosslinked preparation relative to starting material (data not shown). Thus, it seems unlikely that group differences are absent due to problems associated with sample preparation.

\section{Experiment 2. Receptor Distribution $24 \mathrm{~h}$ or 30 Min after Cocaine Challenge}

To evaluate the effect of re-exposure to cocaine on AMPAR distribution, a separate group of rats was given the same pretreatment regimen as in Experiment 1 and then reexposed to cocaine or saline on WD14. As expected, only rats given repeated cocaine injections showed a significant increase in activity between the first and last pretreatment sessions (Figures $4 \mathrm{a}$ and $\mathrm{b}$; main effect of injection, $\mathrm{F}_{(1,506)}=21.7, \quad p<0.0001 ; \quad$ injection $\times$ time interaction, $\mathrm{F}_{(1,506)}=12.9, p<0.0001$; Sal $N=21$, Coc $\left.N=24\right)$. Fourteen days after the last pretreatment injection, rats were brought back to the activity monitors and, after a $40 \mathrm{~min}$ habituation period, were given a challenge injection of cocaine or saline (Figures $4 \mathrm{c}, \mathrm{d}$ ). The locomotor response to saline challenge did not differ between saline- and cocaine-pretreated rats (Figure 4c; Sal-Sal $N=9$, Coc-Sal $N=12$ ). However, cocaine-pretreated rats challenged with cocaine showed significantly greater locomotor activity than saline-pretreated rats experiencing cocaine for the first time (Figure 4d; main effect of group, $\mathrm{F}_{(2,264)}=4.1, p<0.05$; group $\times$ time interaction, $\mathrm{F}_{(22,264)}=2.0, p<0.01$; Coc-Coc $N=12$, Sal-Coc $N=12$ ). Thus, using this cocaine-pretreatment regimen, the robust expression of sensitization on WD14 (Figure 4) coincides with the ability to show AMPAR upregulation in NAc but not DS (WD15; Figures 2 and 3, respectively).

Twenty-four hours after the challenge injection (WD15), NAc and DS tissues were removed and crosslinked, and AMPAR subunit distribution was evaluated (Figure 5). The GluR1 S/I ratio was significantly decreased by cocaine challenge in both saline- and cocaine-pretreated groups (Figure 5a; main effect of challenge, $\mathrm{F}_{(1,34)}=6.4, p<0.05$;

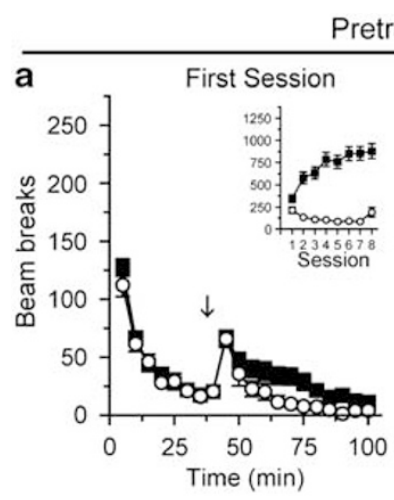

Pretreatment

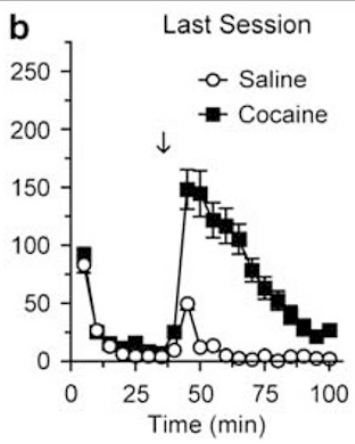

Challenge on WD 14

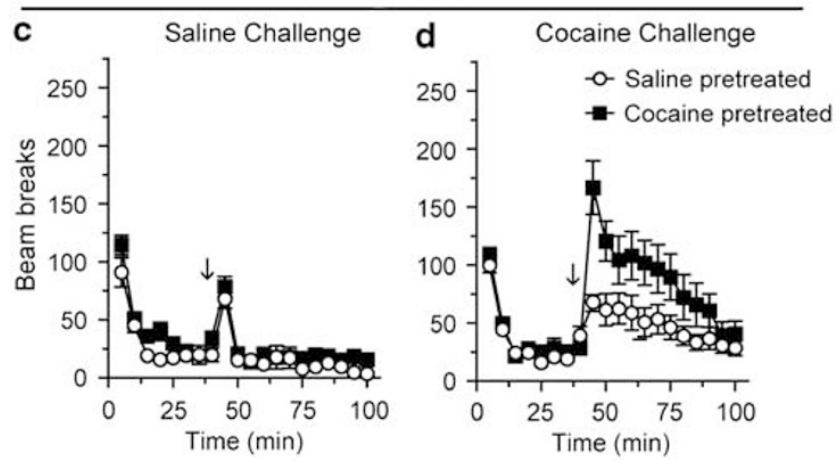

Figure 4 Locomotor sensitization is expressed on withdrawal day 14 (WDI4), when AMPAR surface expression is enhanced in the NAc. Data are expressed as average number of beam breaks per 5 min interval during the first and last pretreatment sessions ( $a$ and $b$, respectively) and after saline or cocaine challenge on WDI4 ( $c$ and d, respectively). The arrow indicates time of injection after habituation and the inset in (a) shows the total number of beam breaks (summed over the first 40 min after injection) across all eight pretreatment injections. Cocaine-pretreated rats showed a greater response to the last pretreatment injection of cocaine compared with the first ( $a, b$; closed squares) and a greater response to cocaine challenge than saline-pretreated rats (d; closed squares vs open circles). Sal-Sal $N=9$, Sal-Coc $N=12, \operatorname{Coc}-S a l N=12, \operatorname{Coc}-\operatorname{Coc} N=12$.

main effect of pretreatment, not significant (NS); pretreatment group $\times$ challenge interaction, NS; Sal-Sal $N=8$, SalCoc $N=10$, Coc-Sal $N=10$, Coc-Coc $N=10$ ). GluR2 distribution was not significantly altered by cocaine challenge in either saline- or cocaine-pretreated groups, although there was a small trend toward decreased S/I (Figure 5b). However, both groups showed significantly decreased surface GluR2/3 $24 \mathrm{~h}$ after challenge (Figure 5c; main effect of challenge, $\mathrm{F}_{(1,36)}=6.7, p<0.05$; main effect of pretreatment, NS; pretreatment group $\times$ challenge interaction, NS) and increased intracellular GluR2/3 (Figure 5c; main effect of challenge, $\mathrm{F}_{(1,36)}=4.7, p<0.05$; main effect of pretreatment, NS; pretreatment group $\times$ challenge interaction, NS), resulting in a significantly decreased S/I ratio (Figure 5c; main effect of challenge, $\mathrm{F}_{(1,36)}=13.0, p<0.001$; main effect of pretreatment, NS; pretreatment $\times$ challenge interaction, NS). Thus, both saline-pretreated and cocainepretreated groups respond to cocaine challenge with a significant decrease in AMPAR surface expression in NAc. In both pretreatment groups, significant decreases were observed for GluR1 and GluR2/3 but only a small trend toward decreased GluR2 was found. This suggests that several types of AMPAR internalize within the $24 \mathrm{~h}$ after 
a
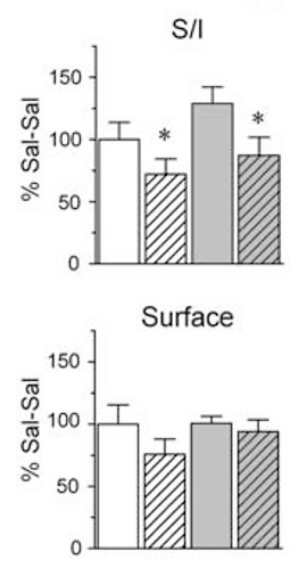

GluR1 NAc
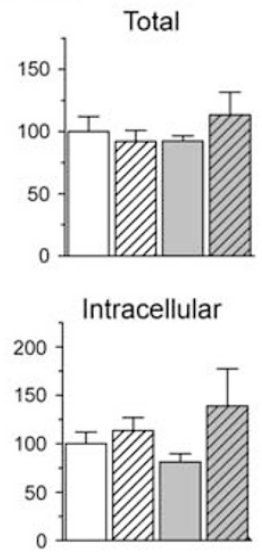

b
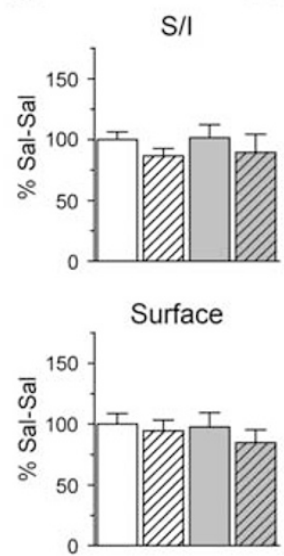

GluR2 NAc
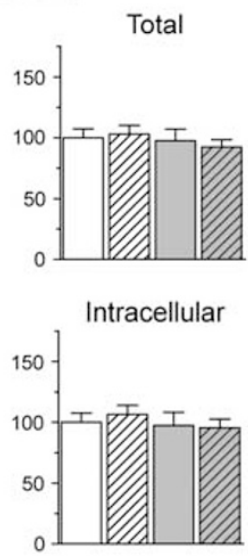

C

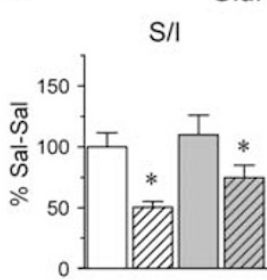

GluR2/3 NAc
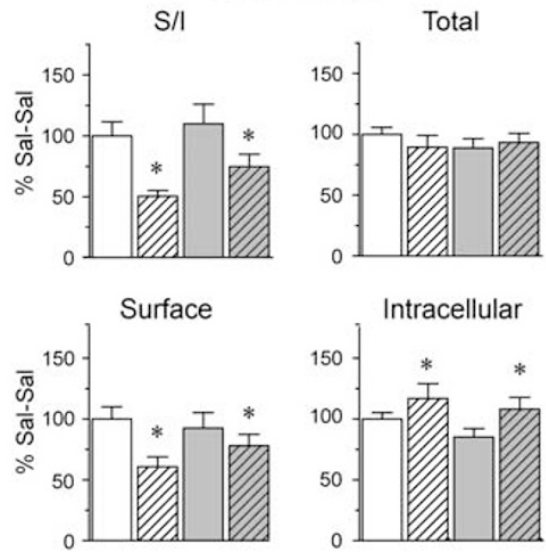

$\square$ Saline-Saline Saline-Cocaine

$\square$ Cocaine-Saline

Cocaine-Cocaine

Figure 5 AMPAR surface expression in the NAc of saline- and cocaine-pretreated rats is decreased $24 \mathrm{~h}$ after cocaine challenge. A challenge injection of saline or cocaine was given on WD I4. Data are expressed as average percent change from saline-saline controls for $\mathrm{GluRI}$ (a; Sal-Sal $\mathrm{N}=8$, Sal-Coc $N=10$, Coc-Sal $N=10$, Coc-Coc $N=10$ ), GluR2 (b; Sal-Sal $N=8$, Sal-Coc $N=10$, Coc-Sal $N=10$, Coc-Coc $N=1$ I), and GluR2/3 (c; Sal-Sal $N=9$, Sal-Coc $N=9$, Coc-Sal $N=10$, Coc-Coc $N=12)$. The GluRI surface/intracellular ratio $(S / I)$ was significantly decreased by cocaine challenge in both salineand cocaine-pretreated groups (a, hatched bars), whereas GluR2 was not significantly altered (b). Surface GluR2/3 and the GluR2/3 S/I ratio were significantly decreased by cocaine challenge in both pretreatment groups, whereas intracellular GluR2/3 was significantly increased (c, hatched bars; * $<<0.05)$.

cocaine challenge, most likely including GluR1/3, but perhaps also including GluR1/2, GluR2/3, or homomeric GluR1 or GluR3 (see discussion in previous section about the difficulties in inferring subunit composition from data on individual subunits). Recalling that surface expression of GluR1/2-containing AMPAR is increased after withdrawal (Figure 2), these results suggest that different AMPAR populations may undergo redistribution during withdrawal $v s$ after re-exposure to cocaine. Using a different cocaine regimen, we previously found similar but not identical results in sensitized rats (Boudreau et al, 2007). GluR1 surface expression decreased markedly $24 \mathrm{~h}$ after cocaine challenge, whereas the GluR2 response to challenge was less pronounced. However, in this earlier study, performed at a time when available lots of GluR3 antibody recognized crosslinked GluR3, GluR3 surface expression was measured directly and did not change significantly after withdrawal or challenge. Most cocaine injections were given in the home cage in our earlier study (Boudreau et al, 2007), whereas all injections were given in a novel environment in this study. Environmental context influences the neuronal circuitry engaged by psychostimulants (eg, Uslaner et al, 2001). Thus, environment-related differences in the effects of psychostimulants on glutamate inputs to NAc neurons may account for apparent differences in postsynaptic AMPAR plasticity in the two sensitization regimens. Variability in antibody lots over time, which can be significant, may also have contributed to the difference and is always a source of potential concern when different results are obtained with GluR2/3 versus GluR2 antibodies.

When DS tissue was examined $24 \mathrm{~h}$ after challenge, ANOVA indicated no significant difference in GluR1 expression between experimental groups (Sal-Sal $N=9$, Sal-Coc $N=11$, Coc-Sal $N=12$, Coc-Coc $N=11$ ). However, two-tailed $t$-tests revealed a significant increase in GluR1 surface expression in the Sal-Coc group $v s$ the Sal-Sal group $(t=2.21, \mathrm{df}=19, p<0.05)$ and a trend toward increased
GluR1 S/I $\left(\mathrm{t}_{19}=1.94, \mathrm{df}=19, p=0.06\right.$; Figure 6a). GluR2 expression was unaltered for both saline- and cocainepretreated rats challenged with cocaine (Figure 6b), although a small trend toward an increased GluR2 S/I ratio was observed in the Sal-Coc group. The GluR2/3 S/I ratio was significantly increased in both cocaine challenged groups (Figure $6 \mathrm{c}$; main effect of challenge, $\mathrm{F}_{(1,39)}=4.4$, $p<0.05$; main effect pretreatment, NS; pretreatment groupchallenge interaction, NS); there was also a trend toward increased GluR2/3 surface expression, but it did not attain statistical significance (main effect of challenge, $F_{(1,39)}=3.6$, $p=0.06$ ). Together with results in Figure 3 (withdrawal only), it appears that, in the DS of cocaine-sensitized rats, GluR3-containing receptors internalize during withdrawal but increase on the cell surface after cocaine challenge. In the DS of saline rats exposed to cocaine for the first time, AMPAR surface expression also increases (GluR1, 2, and 3 may contribute). Given that NMDAR distribution in the DS and NAc was not significantly altered by cocaine withdrawal in Experiment 1, NMDAR distribution was not evaluated after challenge injections.

To determine if AMPAR redistribution occurred soon after cocaine challenge, additional rats were pretreated with cocaine. NAc and DS tissue was collected $30 \mathrm{~min}$ after a saline or challenge (Coc-Sal/30 min, Coc-Coc/30 min) or after 14 days of withdrawal alone (Coc-WD14). Locomotor sensitization was evident across pretreatment (first $v s$ last pretreatment injection: main effect of injection, $\mathrm{F}_{(1,255)}=31.9, \quad p<0.0001 ; \quad$ injection $\times$ time interaction, $\left.\mathrm{F}_{(5,255)}=5.2, p<0.0001\right)$ as well as after cocaine challenge (first pretreatment injection $v s$ cocaine challenge: session $\times$ time interaction, $\mathrm{F}_{(5,170)}=2.7, p<0.05$; see Supplementary Figure 2 for graphs). Compared with the Coc-WD14 group, rats challenged with either cocaine or saline showed no significant changes in GluR1 surface expression in the NAc (Supplementary Figure 3a). There was a trend toward decreased GluR2/3 expression $(\sim 20 \%$ 
a
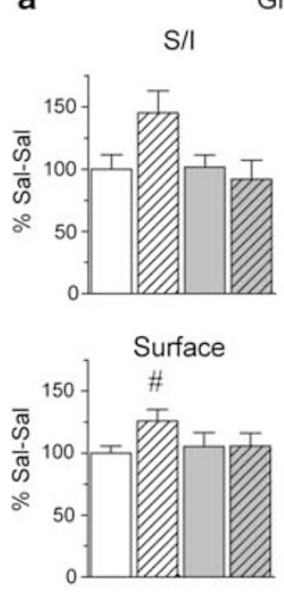

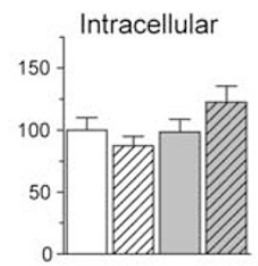

b

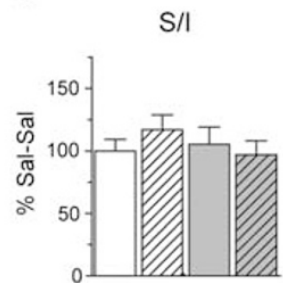

GluR2 DS
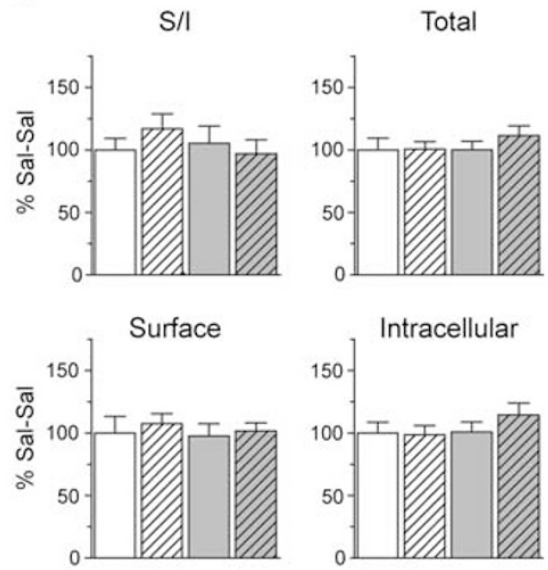

C

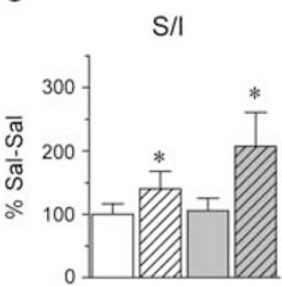

GluR2/3 DS

Total

\section{$\square$ Saline-Saline $\square$ Saline-Cocaine $\square$ Cocaine-Saline Cocaine-Cocaine}

Figure 6 AMPAR surface expression in the DS of cocaine-pretreated rats is increased $24 \mathrm{~h}$ after cocaine challenge. A challenge injection of saline or cocaine was given on withdrawal day I4. Average percent change from saline-saline controls for GluRI (a; Sal-Sal N=9, Sal-Coc N=II, Coc-Sal N= I2, $\operatorname{Coc}-\operatorname{Coc} N=11$ ), GluR2 (b; Sal-Sal $N=9$, Sal-Coc $N=12$, Coc-Sal $N=12, \operatorname{Coc}-\operatorname{Coc} N=12$ ), and GluR2/3 (c; Sal-Sal $N=9$, Sal-Coc $N=11$, Coc-Sal $N=12$, Coc-Coc $N=11)$. The Sal-Coc group showed a significant increase in surface GluRI ${ }^{\#} p<0.05$; $t$-test vs Sal-Sal) and trends toward an increased surface/intracellular ratio (S/I) for GluRI (a) and GluR2 (b). The GluR2/3 S/I ratio was significantly increased for both Sal-Coc and Coc-Coc groups $(* 0$ 0.05). Please note that panel $c$ has a different $x$ axis scale than panels $a$ and $b$.

a

GluR1 DS

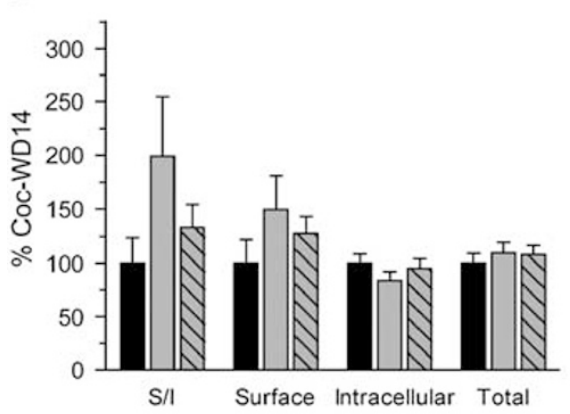

b

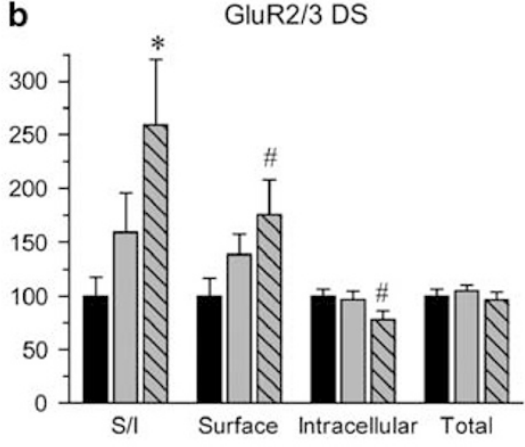

Coc-WD14 $\square$ Coc-Sal30min $₫ \square \mathrm{Coc}-\mathrm{Coc} / 30 \mathrm{~min}$

Figure 7 AMPAR surface expression in the DS on withdrawal day 14 (Coc-WDI4) or 30 min after cocaine or saline challenge on withdrawal day I4 (Coc-Sal/30 min and Coc-Coc/30 min). Data are expressed as average percent change from the Coc-WDI4 group for GluRI (a) and GluR2/3 (b). GluRI surface expression appeared increased after challenge injections (particularly after saline challenge), although these changes did not reach statistical significance $(p>0.1)$. GluR2/3 surface expression and the S/I ratio were significantly increased after cocaine challenge, whereas GluR2/3 intracellular levels were significantly decreased; together, these results suggest redistribution of GluR2/3 containing receptors to the surface. A small increase in GluR2/3 surface expression was also observed after saline challenge but did not reach statistical significance $(p>0.1) . N=9$ for all groups. ${ }^{*} p<0.05 ;{ }^{*} p=0.05$.

decrease) in both saline and cocaine challenged groups (Supplementary Figure 3b). Taken together, these data suggest that some redistribution of GluR2- or GluR3containing AMPAR may occur in the NAc within 30 min after challenge, but this is unlikely to be related to the expression of sensitization, as it is observed after either saline or cocaine challenge.

In DS, GluR1 expression was not significantly altered 30 min after cocaine or saline challenge. However, a trend toward increased GluR1 surface expression was observed for both saline and cocaine challenged groups compared with withdrawal only; in contrast to GluR2/3 effects (see next sentence) the GluR1 trend was more pronounced after saline challenge (Figure 7a). GluR2/3 surface expression and the $S / I$ ratio were significantly increased after cocaine challenge (Figure $7 \mathrm{~b}$; unpaired $t$-test: CocWD14 vs Coc-Coc/30 min; GluR2/3 surface: $\mathrm{t}_{16}=2.0$, $\left.p=0.05 ; \mathrm{S} / \mathrm{I}: \mathrm{t}_{16}=2.5, p<0.05\right)$. Furthermore, intracellular GluR2/3 was significantly decreased after cocaine challenge (Figure $7 \mathrm{~b} ; \mathrm{t}_{16}=2.1, p=0.05$ ) consistent with the redistribution of GluR2-or GluR3-containing receptors to the cell surface. After saline challenge, trends toward increased GluR2/3 surface expression and S/I ratio were also observed but did not reach significance (Coc-WD14 vs Coc-Sal/ 30 min; surface: $\mathrm{t}_{16}=1.5, p=0.15 ; \mathrm{S} / \mathrm{I}: \mathrm{t}_{16}=1.4, p=0.17$ ). As described above, the GluR2/3 S/I ratio was increased in DS $24 \mathrm{~h}$ after either cocaine or saline challenge (Figure 6). Thus, redistribution of GluR2- or GluR3-containing AMPAR in the DS appears to be initiated soon after cocaine challenge and maintained for $24 \mathrm{~h}$ in rats previously exposed to the drug. Cocaine-pretreated rats given a saline challenge also show increased GluR2/3 surface expression, but this does not achieve significance until $24 \mathrm{~h}$ after the injection. 
Experiment 3. Do Decreases in AMPAR Surface Expression or AMPAR Transmission Affect the Expression of Locomotor Sensitization?

The relationship of locomotor sensitization to AMPAR upregulation after withdrawal or AMPAR internalization after drug challenge is unclear. If enhanced AMPAR surface expression is required for expression of locomotor sensitization, then AMPAR internalization in the NAc produced by cocaine challenge might interfere with subsequent expression of the sensitized response. To test this, additional rats $(N=12)$ received repeated cocaine treatment followed by cocaine challenge on WD14. Twenty-four hours later, when AMPAR surface expression in the NAc is reduced in rats challenged with cocaine (Experiment 2), we administered a second cocaine challenge and measured the locomotor response. As expected, there was a significantly greater locomotor response to the last $v s$ first cocainepretreatment injection (Figure 8a; time $\times$ injection interaction, $\left.\mathrm{F}_{(11,242)}=5.20, p<0.0001\right)$ and, similar to Experiment 2 above, rats exhibited a sensitized response to the first cocaine challenge on WD14 (Figure 8a; challenge 1 vs first pretreatment injection; main effect of injection, $\mathrm{F}_{(1,242)}=5.7, \quad p<0.05 ; \quad$ time $\times$ injection interaction, $\left.\mathrm{F}_{(11,242)}=5.25, p<0.0001\right)$. However, the locomotor response to the second cocaine challenge on WD15 was identical to the response to the first challenge on WD14 (Figure $8 \mathrm{a}$ and $\mathrm{b}$ ), and neither differed significantly from the last pretreatment injection (Figure $8 \mathrm{~b}$ ).

The simplest interpretation of this 'double challenge' experiment is that expression of locomotor sensitization is not compromised by a reduction in AMPAR surface expression in the NAc. However, it is theoretically possible that the second re-exposure to the testing environment on WD15 rapidly altered AMPAR surface expression and thus influenced the locomotor response. Specifically, to support an alternative interpretation of our data, it would be necessary to postulate that the second exposure to the testing environment on WD15 caused rapid reinsertion of the AMPAR (ie, during the 40 min habituation period), such that upregulation was 'restored' just before the cocaine injection. If this were the case, the data could be interpreted as indicating that behavioral responses to cocaine challenge were identical on WD14 and WD15 because AMPAR surface expression was identical on WD14 and WD15. However, we consider this very unlikely. In Supplementary Figure 3, we compare cocaine-sensitized rats killed after withdrawal (no challenge injection) with sensitized rats killed $30 \mathrm{~min}$ after challenge with saline (ie, after re-exposure to the testing context and procedure). No difference in AMPAR surface expression was found between these groups. Similarly, in a previous study in which cocaine self-administration was paired with a context plus a discrete cue for 10 days, we found no changes in AMPAR surface expression $30 \mathrm{~min}$ after re-exposure to the context and cue (see Conrad et al, 2008, Supplementary Materials).

As another approach to determining whether decreased AMPAR transmission in the NAc affects the expression of locomotor sensitization, we infused the competitive AMPAR antagonist CNQX into the NAc core before cocaine challenge. All rats in this experiment $(N=42)$ were pretreated with cocaine for 8 days and exhibited sensitization based on comparison of the locomotor response to the first $v s$ last cocaine injection (Figure 9a; main effect of injection, $\mathrm{F}_{(1,369)}=25.9, p<0.0001$; time $\times$ session interaction, $\left.\mathrm{F}_{(8,369)}=3.1, \quad p<0.0001\right)$. Cocaine-pretreated rats exhibited a similar locomotor response to saline challenge on WD14, regardless of whether they received an intra-NAc infusion of either dose of CNQX or vehicle before the challenge injection (Figure 9c; Veh-Sal $N=10,0.03 \mu \mathrm{g}$ CNQX-Sal $N=6,0.3 \mu \mathrm{g}$ CNQX-Sal $N=5$ ), indicating no effect of CNQX on basal locomotor activity. Similarly, the locomotor response did not differ between CNQX- and vehicle-infused groups given a cocaine challenge (Figure $9 \mathrm{~b}$; Veh-Coc $N=10,0.03 \mu \mathrm{g}$ CNQX-Coc $N=6,0.3 \mu \mathrm{g}$ CNQXCoc $N=5$ ). All cocaine-challenged groups showed a sensitized locomotor response compared with their first cocaine injection (Veh-Coc: main effect of injection,

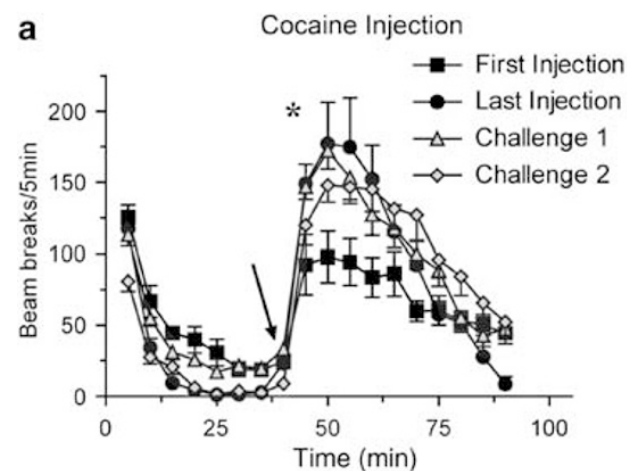

b Activity Post Injection

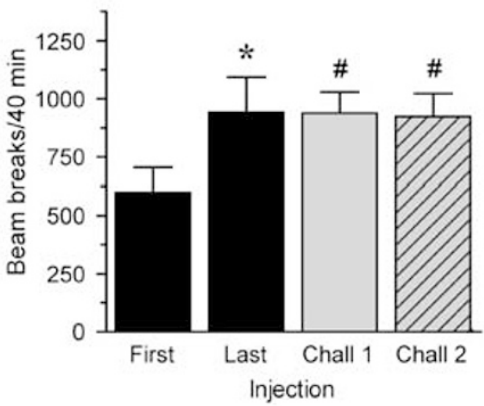

Figure 8 Locomotor sensitization is expressed at a time when AMPAR surface expression in the NAc has been decreased by earlier cocaine challenge. Panel a shows the average number of beam breaks per $5 \mathrm{~min}$ interval during the first (closed squares) and last (closed circles) cocaine-pretreatment sessions and after the first (grey triangles) and second (grey diamonds) cocaine-challenge injection. The first cocaine challenge was administered on WDI4. The second cocaine challenge was administered $24 \mathrm{~h}$ after the first challenge, a time when AMPAR surface expression is decreased in the NAc (see Figure 5). The arrow indicates time of injection after habituation. There was a significant increase in locomotor activity in response to the last (closed circles) vs first injection (closed squares) of cocaine. The locomotor response to the first (grey triangles) and second (grey diamonds) challenge injections did not differ, but both were significantly greater than the response to the first injection of cocaine (closed squares). Panel b shows the average total number of beam breaks summed over the first $40 \mathrm{~min}$ after each injection (*p $<0.05$ for last injection vs first injection; \#indicates no significant difference between last injection, challenge I, and challenge 2). $\operatorname{Coc} N=12$. 
a

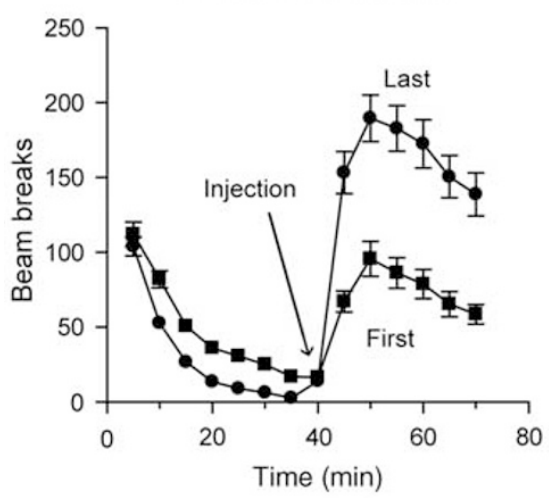

c

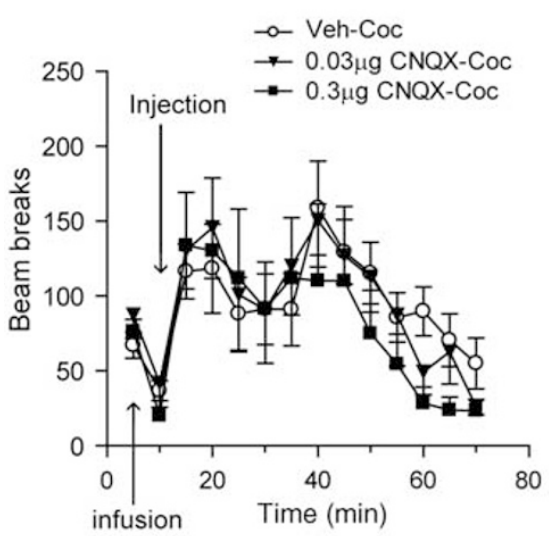

b

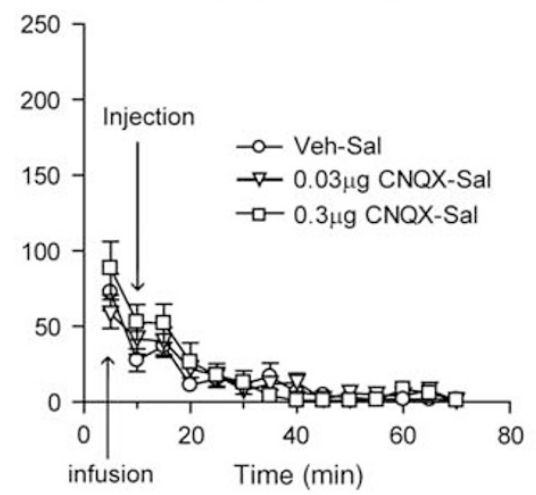

d

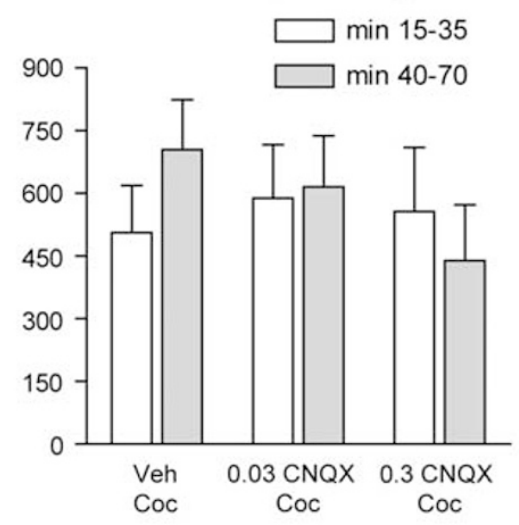

e

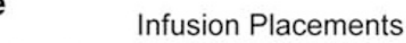


(beginning $25 \mathrm{~min}$ after cocaine challenge and $35 \mathrm{~min}$ after CNQX infusion), particularly since the local CNQX concentration should decrease over time. In earlier studies, CNQX depressed the sensitized locomotor response during the first $20 \mathrm{~min}$ (Bell et al, 2000) and $45 \mathrm{~min}$ (Pierce et al, 1996) after cocaine challenge, whereas no effect was present early in the test session in our study. Overall, our results indicate that the cocaine-pretreatment regimen used here produces sensitization that can be expressed even after AMPAR transmission is decreased by CNQX. These results are consistent with those obtained in the 'double challenge' experiment (see above).

\section{Experiment 4. Does Cocaine Challenge Produce a Transient or a Long-Lasting Decrease in AMPAR Surface Expression?}

AMPAR surface expression in the NAc was decreased $24 \mathrm{~h}$ after a cocaine challenge in both cocaine- and salinepretreated rats (Figure 5). If this decrease persisted, it would argue against a role for enhanced AMPAR surface expression in long-lasting cocaine-induced behavioral changes. Therefore, to determine whether decreased AMPAR surface expression is a transient or long-lasting effect in cocainepretreated rats, a third group of rats was given repeated cocaine injections $(N=28)$. After 14 days of withdrawal, some were challenged with cocaine as described for Experiment 2 (Coc-Coc/WD21 $N=13$ ), whereas the other half remained in the animal colony (Coc-WD21 $N=15$ ). After an additional 7 days of withdrawal, NAc tissue was collected and AMPAR distribution was evaluated. Cocaine pretreatment resulted in behavioral sensitization similar to that seen in other experiments (data not shown; main effect of injection, $\mathrm{F}_{(1,594)}=11.8, \quad p<0.0001$; time $\times$ injection interaction, $\left.\mathrm{F}_{(11,594)}=7.0, p<0.0001\right)$. Surface, intracellular, and total levels of GluR1 did not differ between Coc-WD21 and Coc-Coc/WD21 groups (Figure 10). Together with other results, this suggests that AMPAR in the NAc are

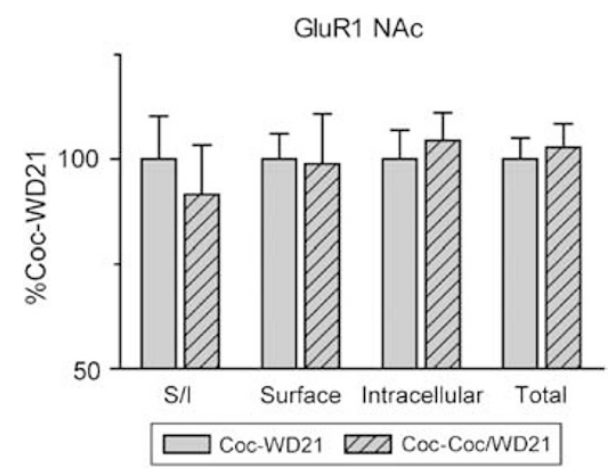

Figure 10 Additional withdrawal after cocaine challenge results in levels of GluRI surface expression comparable with those observed after withdrawal only (no cocaine challenge). All rats received eight pretreatment injections of cocaine and developed locomotor sensitization (not shown). For some rats, tissue was collected on WD2 I without any further exposure to cocaine (Coc-WD2I $N=15$; solid bars). Other rats received a cocaine challenge on WDI4, followed by 7 additional days of withdrawal before collection of tissue on WD2I (Coc-Coc/WD2I $N=13$; hatched bars). Data are expressed as percent of Coc-WD2I values. GluRI measures did not differ between groups. internalized $24 \mathrm{~h}$ after cocaine challenge, but their surface expression recovers to levels comparable with unchallenged cocaine-pretreated rats after an additional 7 days of withdrawal.

\section{DISCUSSION}

We used a cocaine regimen that consistently produces locomotor sensitization ( $\mathrm{Li}$ et al, 2004) to examine the relationship between sensitization and the distribution of AMPAR and NMDAR in the NAc and DS. In discussing the related literature, we have emphasized studies of glutamate receptor subunit protein levels in cell surface or synaptic fractions. For a comprehensive review of older studies measuring total tissue levels of glutamate receptor subunits, see Wolf (2002).

\section{Relationship Between Increased AMPAR Surface Expression in NAc and Locomotor Sensitization}

The NAc is critical for the expression of sensitization (Pierce and Kalivas, 1997; Vanderschuren and Kaliavs 2000) and this implies a requirement for some AMPAR tone, given that AMPAR provide the major excitatory drive to NAc neurons (Pennartz et al, 1990; $\mathrm{Hu}$ and White, 1996), although it is clear that DA receptor stimulation also has a necessary role (eg, Pierce and Kalivas, 1997). The main question addressed here is whether the enhanced locomotor response associated with the expression of sensitization can be directly linked to an enhancement of AMPAR surface expression. Our results, along with others discussed below, suggest that this is not the case. First, the two can be dissociated temporally; locomotor sensitization is expressed on WD1, but AMPAR upregulation develops later, sometime between WD1 and WD7, and then persists at least through WD21 (Boudreau and Wolf, 2005; Boudreau et al, 2007; 2009). Other results are consistent with this time course of AMPAR upregulation in cocaine-sensitized rodents (Fitzgerald et al, 1996; Churchill et al, 1999; Scheggi et al, 2002; Kourrich et al, 2007; Ghasemzadeh et al, 2009). Second, experimentally induced decreases in AMPAR surface expression or transmission after withdrawal from cocaine pretreatment do not prevent the expression of locomotor sensitization. This was shown in two ways: (1) administering a challenge injection of cocaine on WD14 (which decreases AMPAR surface expression in the NAc $24 \mathrm{~h}$ later; Thomas et al, 2001; Boudreau et al, 2007; Kourrich et al, 2007; present results) did not alter the locomotor response to a second cocaine challenge on WD15. Similarly, although intra-NAc AMPA was less efficacious at eliciting locomotion $24 \mathrm{~h}$ after a cocaine challenge, systemic cocaine challenge still elicited a sensitized locomotor response at this time and, in fact, the response was more robust (Bachtell and Self, 2008). (2) Decreasing AMPAR transmission in the NAc of sensitized rats through intracranial infusion of CNQX also failed to prevent the expression of locomotor sensitization (see below). In addition to these two lines of evidence, viral overexpression of GluR1 in the NAc during withdrawal attenuated the sensitized response to cocaine challenge, whereas dominant negative GluR1 enhanced the response 
(Bachtell et al, 2008). Interpretation of the latter results is complex because exogenous AMPAR plasticity was superimposed on endogenous AMPAR plasticity, but they do not support the idea that AMPAR upregulation underlies locomotor sensitization.

As noted above, we found that intra-NAc core infusion of the AMPAR antagonist CNQX did not prevent the expression of sensitization in response to cocaine challenge on WD14, although it did produce a trend toward suppression of locomotion during the later portion of the test session. If enhanced AMPAR transmission was required for the expression of locomotor sensitization, then expression of sensitization should be affected by decreasing AMPAR transmission with CNQX or producing AMPAR internalization with cocaine challenge in the double challenge experiment (above). The fact that neither manipulation produced an effect argues that the expression of sensitization can be maintained despite some reduction in AMPAR transmission. This is not to say that AMPAR tone in the NAc core is completely dispensable with respect to the expression of sensitization. Indeed, intracranial infusion of drug into a structure the size of the NAc seems unlikely to produce a complete block of neurotransmission. Furthermore, in light of the critical role of AMPAR transmission in providing excitatory drive to MSN (above), it is likely that a complete block, if achieved, would interfere with most behavioral responses involving NAc. It should be emphasized that our experiments were designed to test the hypothesis that enhanced AMPAR surface expression is required for the expression of locomotor sensitization, not to determine if there is an absolute requirement for some level of AMPAR transmission. Finally, it is important to note that our CNQX infusions into NAc core do not address the role of AMPAR transmission in the NAc shell in the expression of sensitization (but see Todtenkopf et al, 2002) or the role of AMPAR transmission in the DS.

Two earlier studies found that intra-NAc core CNQX blocked the expression of sensitization to cocaine (Pierce et al, 1996; Bell et al, 2000; the same CNQX concentrations were used in our study and in these studies). Significant procedural differences may have contributed to the discrepancy (see below), but one important consideration is that CNQX is a competitive antagonist and its ability to block AMPAR transmission is therefore dependent on the level of presynaptic glutamate release. This in turn may differ between laboratories given that presynaptic glutamate release is affected by variables such as stress (Moghaddam, 1993) and perhaps by the magnitude of sensitization. With respect to the latter, it should be noted that the magnitude of sensitization appeared greater in our study than in Bell et al (2000) (compare Figures 2 and 3 in Bell et al, 2000 with Figures 1 and 4 here), even though they used a nearly identical cocaine regimen. Another potentially important variable is withdrawal time. The earlier studies (Pierce et al, 1996; Bell et al, 2000) were performed after longer withdrawals (WD21 and WD14-23, respectively). It is well known that sensitization expression mechanisms can be withdrawal-dependent (Vanderschuren and Kaliavs 2000) and we have demonstrated that signaling pathways involved in cocaine's actions undergo dynamic changes in activity in the NAc of cocaine-sensitized rats over 3 weeks of withdrawal (Boudreau et al, 2009). Differences between our results and Pierce et al (1996) may also reflect the differences in cocaine regimen and drug administration environment.

In conclusion, neither cocaine-induced AMPAR internalization nor intra-NAc infusion of CNQX is expected to completely eliminate AMPAR tone, so our results should not be interpreted to suggest that sensitization can occur in the absence of AMPAR transmission. Rather, our results, along with those of others (Boudreau and Wolf, 2005; Bachtell and Self, 2008; Bachtell et al, 2008), argue that enhanced AMPAR surface expression is not required for the expression of locomotor sensitization, because treatments that certainly decrease AMPAR surface expression (cocaine challenge) or AMPAR activation (intra-NAc CNQX) do not alter its magnitude.

\section{Relationship between AMPAR Internalization after Cocaine Challenge and the Expression of Locomotor Sensitization}

To determine if AMPAR rapidly internalize after cocaine challenge, saline- and cocaine-pretreated rats were killed $30 \mathrm{~min}$ after cocaine challenge. Cocaine-pretreated rats expressed sensitization, but GluR1 surface expression was unaltered. A trend toward decreased surface GluR2/3 was found, but this was also observed after saline challenge. These data do not support a role for rapid AMPAR internalization in the expression of locomotor sensitization to cocaine, although it remains possible that AMPAR trafficking linked to locomotor sensitization occurs in micro-domains that our experiments cannot assess (eg, the postsynaptic density). Interestingly, $24 \mathrm{~h}$ after cocaine challenge, GluR1 and GluR2 surface expression was decreased in both saline-pretreated rats experiencing cocaine for the first time and cocaine-pretreated rats that were re-exposed to the drug, arguing against a relationship between AMPAR internalization and previous cocaine history. However, Kourrich et al (2007) found a decreased AMPA/NMDA ratio in the NAc shell $24 \mathrm{~h}$ after cocaine challenge in cocaine- but not saline-pretreated mice.

In amphetamine-sensitized rats, some data (Brebner et al, 2005) but not others (Tucker et al, 2008) support a role for rapid AMPAR internalization in the expression of locomotor sensitization. However, amphetamine-sensitized rats do not exhibit increased AMPAR surface expression after withdrawal or decreased GluR1 surface expression $24 \mathrm{~h}$ after amphetamine challenge (Nelson et al, 2009). Thus, results of Brebner et al (2005) should not be extrapolated to cocaine, because cocaine and amphetamine have very different effects on AMPAR distribution. These differences raise interesting questions about cross-sensitization of both the locomotor activating and incentive motivational properties of these drugs.

\section{Relationship between AMPAR Upregulation in the NAc and Drug Seeking}

Cocaine pretreatment enhances drug seeking and other drug-motivated behaviors (Horger et al, 1990; Lett, 1989; De Vries et al, 1998, 2002; Vezina, 2004). We suggest that the AMPAR upregulation observed in the NAc in association with locomotor sensitization to cocaine may contribute 
to this enhancement. Consistent with this idea, drug seeking is blocked by intra-NAc infusion of AMPAR antagonists and is elicited by intra-NAc infusion of AMPA (Cornish et al, 1999; Cornish and Kalivas 2000; Di Ciano and Everitt 2001; Suto et al, 2004; Backstrom and Hyytia 2006; Famous et al, 2008; Ping et al, 2008). In addition, increased surface expression of GluR1-containing AMPAR is linked to incubation of cocaine craving (Conrad et al, 2008) and cocaine-primed reinstatement (Anderson et al, 2008), although a different AMPAR population may internalize in association with reinstatement (Famous et al, 2008).

Although AMPAR surface expression was decreased $24 \mathrm{~h}$ after cocaine challenge, after 7 additional days of withdrawal it no longer differed from levels in unchallenged cocaine-sensitized rats. Recovery of AMPAR transmission after challenge has also been shown behaviorally (Bachtell and Self, 2008). Persistence of AMPAR upregulation, despite temporary decreases after cocaine challenge, is consistent with a role in persistent alterations in drug seeking after exposure to sensitizing psychostimulant regimens. However, the amphetamine results described above suggest that amphetamine sensitization must facilitate subsequent amphetamine seeking (Vezina, 2004) through mechanisms other than AMPAR upregulation.

\section{AMPAR in the Dorsal Striatum}

Results in DS differed considerably from those in the NAc. Although cocaine-sensitized rats on WD15 showed increased AMPAR surface expression in the NAc, decreases occurred in the DS. In cocaine-sensitized rats challenged with cocaine, AMPAR surface expression was decreased $24 \mathrm{~h}$ later in the NAc, whereas AMPAR in DS redistributed to the cell surface within $30 \mathrm{~min}$ after re-exposure to cocaine, and this was maintained for at least $24 \mathrm{~h}$. The NAc and DS differed not only in the direction of AMPAR changes, but also in the AMPAR subunits affected. For example, after withdrawal, the largest effects were found with GluR1 and GluR2 antibodies in the NAc but with the GluR2/3 antibody in the DS. Subunit differences were also found after cocaine challenge. As most forms of AMPAR plasticity are triggered by changes in presynaptic glutamate activity, we speculate that different AMPAR trafficking in NAc $v s$ DS reflects different effects of cocaine on activity of glutamate inputs to these regions. The lateral portion of DS examined here receives glutamate inputs primarily from sensorimotor regions of cortex, whereas glutamate inputs to the NAc arise from limbic regions (McGeorge and Faull, 1989).

Consistent with our results, Ghasemzadeh et al (2009) observed increased levels of GluR1 and GluR2 in a synaptosomal membrane fraction prepared from the NAc, but not DS, of cocaine-sensitized rats on WD21. In an earlier study measuring total AMPAR subunit levels in DS, GluR1 and GluR2/3 were not significantly altered on WD21, although there was a trend toward decreased GluR2/3 ( $87 \pm 12 \%$ of control), reminiscent of our results (Churchill et al, 1999). A study of cocaine sensitization in juvenile mice found significantly increased GluR1 and GluR2 surface expression in the DS on WD1; trends toward increases were observed in NAc of juvenile mice and in both NAc and DS of young adult mice (Kim et al, 2009). Differences from our results may reflect withdrawal time or species differences.

\section{NMDAR Distribution in the NAc and DS of Cocaine-Sensitized Rats}

No significant alterations in NMDAR surface or total expression were found in the NAc or DS on WD15. However, trends toward increased surface, intracellular, and total levels in the NAc were found with the NR2A/B antibody, but not the NR2B antibody, indicating a possible increase in NR2A. The appearance of NR2B-containing silent synapses has recently been demonstrated in the NAc shell of cocaine-sensitized rats on WD1-2 (Huang et al, 2009). Taken together, this may suggest that new NR2Bcontaining silent synapses are replaced by NR2A-containing synapses after longer withdrawal periods. In apparent contrast to these results, Kourrich et al (2007) observed increased AMPAR but not NMDAR currents on WD10-14 in the NAc shell of cocaine-sensitized mice. However, these investigators sampled NMDAR from AMPAR-containing synapses, and thus would not have detected NMDAR in silent synapses; procedural and species differences may also be significant. Two studies found increased levels of NMDAR subunits (and GluR1) in synaptosomal membrane fractions prepared from the NAc of cocaine-sensitized rats. Ghasemzadeh et al (2009) observed increased NR1, NR2A, and NR2B in core and shell on WD21 but not WD1. Schumann and Yaka (2009) observed increases in the same subunits on WD7 and WD21 (similar to our study, the dissection included core and shell). It should be noted that synaptosomal membrane fractions contain both surface and intracellular receptors as well as non-synaptic membrane. Earlier studies measuring total tissue levels of NMDAR subunits in the NAc by western blotting also found withdrawal-dependent increases in their expression. Although NR1 was unchanged on WD1 (Fitzgerald et al, 1996; Churchill et al, 1999), one study found a trend toward increased NR1 on WD21 (although this was mainly attributable to rats that failed to sensitize; Churchill et al, 1999), whereas Scheggi et al (2002) found significant increases in NR1 and NR2B (but not NR2A) on WD21. Using immunohistochemistry, Loftis and Janowsky (2000) found that NR2B was decreased in NAc shell but not core of sensitized rats on WD1, unchanged on WD3, and increased in both core and shell on WD14. Interestingly, Schumann and Yaka (2009) found that systemic injection of an NR2Bselective antagonist (on each cocaine pretreatment day) blocked both the induction of behavioral sensitization and the increased synaptosomal membrane levels of NMDAR subunits and GluR1 observed after withdrawal, consistent with other data indicating an early role for NR2B transmission (Huang et al, 2009).

The relationship between AMPAR and NMDAR plasticity in sensitization is interesting to consider in light of the fact that various cocaine regimens (Robinson and Kolb, 2004; Lee et al, 2006; Ferrario et al, 2005), including the one used here (Li et al, 2004), produce increased spine density in the NAc as detected with Golgi-Cox staining. Recent work suggests that this may reflect a switch from small diameter spines to larger diameter spines (Shen et al, 2009). It is possible that the larger spines are more likely to bear 
synapses (Holtmaat and Svoboda, 2009). Indeed, AMPAR synaptic insertion can be coupled to spine enlargement (eg, Kopec et al, 2007), suggesting a potential link between increased surface AMPAR levels and spine changes in the NAc of sensitized rats. It is not known whether these postsynaptic changes translate into an increase in functional synaptic contacts (ie, is there a corresponding presynaptic expansion?). If this is the case, enhanced NMDAR levels might also have been expected, because the presence of NMDAR precedes the addition of AMPAR both during maturation of young synapses during development and the unsilencing of synapses (Constantine-Paton and Cline, 1998), although there is precedent for AMPAR-only synapses in the cerebellum (Clark and Cull-Candy, 2002). Somewhat surprisingly, neither AMPAR nor NMDAR surface expression is increased in amphetamine-sensitized rats on WD21 (Nelson et al, 2009), although repeated amphetamine can also increase dendritic spine density in NAc (Robinson and Kolb, 2004). Studying the relationship between cocaine's effects on spine morphology and excitatory transmission (Shen et al, 2009) will help unravel this puzzle.

\section{CONCLUSION}

We examined AMPAR surface expression in the NAc of cocaine-sensitized rats under a variety of conditions. Multiple dissociations between the expression of locomotor sensitization and AMPAR surface expression in the NAc were found. Furthermore, a very different pattern of AMPAR adaptations was observed in the DS. Although AMPAR surface expression in NAc increased after withdrawal and decreased $24 \mathrm{~h}$ but not $30 \mathrm{~min}$ after cocaine challenge in sensitized rats, AMPAR surface expression in DS was decreased after withdrawal but increased $30 \mathrm{~min}$ and $24 \mathrm{~h}$ after cocaine challenge. Furthermore, different AMPAR subunits were affected in the two regions. What then is the functional importance of AMPAR upregulation in the NAc produced by repeated cocaine exposure and associated with locomotor sensitization? We suggest a relationship to subsequent drug-seeking behavior rather than the expression of locomotor sensitization.

\section{ACKNOWLEDGEMENTS}

This work was supported by USPHS Grants DA009621, DA015835, and DA00453 to MEW. CRF was supported by postdoctoral National Research Service Award DA024502. We thank Kerstin A Ford and Peter Campbell for technical assistance. CRF thanks the Santa Fe Institute for their hospitality while this article was written.

\section{DISCLOSURE}

The authors declare that, except for income received from the primary employer, no financial support or compensation has been received from any individual or corporate entity over the past 3 years for research or professional service, and there are no personal financial holdings that could be perceived as constituting a potential conflict of interest.

\section{REFERENCES}

Al-Hallaq RA, Conrads TP, Veenstra TD, Wenthold RJ (2007). NMDA di-heteromeric receptor populations and associated proteins in rat hippocampus. J Neurosci 27: 8334-8343.

Anderson SM, Famous KR, Sadri-Vakili G, Kumaresan V, Schmidt HD, Bass CE et al. (2008). CaMKII: a biochemical bridge linking accumbens dopamine and glutamate systems in cocaine seeking. Nat Neurosci 11: 344-353.

Bachtell RK, Self DW (2008). Renewed cocaine exposure produces transient alterations in nucleus accumbens AMPA receptormediated behavior. J Neurosci 28: 12808-12814.

Bachtell RK, Choi K-H, Simmons DL, Falcon E, Monteggia LM, Neve RL et al. (2008). Role of GluR1 expression in nucleus accumbens neurons in cocaine sensitization and cocaine-seeking behavior. Eur J Neurosci 27: 2229-2240.

Backstrom P, Hyytia P (2006). Ionotropic and metabotropic glutamate receptor antagonism attenuates cue-induced cocaine seeking. Neuropsychopharmacol 31: 778-786.

Bell K, Duffy P, Kalivas PW (2000). Context-specific enhancement of glutamate transmission by cocaine. Neuropsychopharmacol 23: 335-344.

Boudreau AC, Wolf ME (2005). Behavioral sensitization to cocaine is associated with increased AMPA receptor surface expression in the nucleus accumbens. J Neurosci 25: 9144-9151.

Boudreau AC, Reimers JM, Milovanovic M, Wolf ME (2007). Surface AMPA receptors in the rat nucleus accumbens increase during cocaine withdrawal but internalize after cocaine challenge in association with altered activity of mitogenactivated protein kinases. J Neurosci 27: 10621-10635.

Boudreau AC, Ferrario CR, Glucksman MJ, Wolf ME (2009). Signaling pathway adaptations and novel protein kinase A substrates related to behavioral sensitization to cocaine. J Neurochem 110: 363-377.

Brebner K, Wong TP, Liu L, Liu Y, Campsall P, Gray S et al. (2005). Nucleus accumbens long-term depression and the expression of behavioral sensitization. Science 10: 1340-1343.

Churchill L, Swanson CJ, Urbina M, Kalivas PW (1999). Repeated cocaine alters glutamate receptor subunit levels in the nucleus accumbens and ventral tegmental area of rats that develop behavioral sensitization. $J$ Neurochem 72: 2397-2403.

Clark BA, Cull-Candy SG (2002). Activity-dependent recruitment of extrasynaptic NMDA receptor activation at an AMPA receptor-only synapse. J Neurosci 22: 4428-4436.

Conrad KL, Tseng KY, Uejima JL, Reimers JM, Heng LJ, Shaham Y et al. (2008). Formation of accumbens GluR2-lacking AMPA receptors mediates incubation of cocaine craving. Nature 454: 118-121.

Constantine-Paton M, Cline HT (1998). LTP and activitydependent synaptogenesis: the more alike they are, the more different they become. Curr Opin Neurobiol 8: 139-148.

Cornish JL, Duffy P, Kalivas PW (1999). A role for nucleus accumbens glutamate transmission in the relapse to cocaineseeking behavior. Neurosci 93: 1359-1367.

Cornish JL, Kalivas PW (2000). Glutamate transmission in the nucleus accumbens mediates relapse in cocaine addiction. J Neurosci 20: RC89.

De Vries TJ, Schoffelmeer AN, Binnekade R, Mulder AH, Vanderschuren LJ (1998). Drug-induced reinstatement of heroin- and cocaine-seeking behaviour following long-term extinction is associated with expression of behavioural sensitization. Eur J Neurosci 10: 3565-3571.

De Vries TJ, Schoffelmeer AN, Binnekade R, Raaso H, Vanderschuren LJ (2002). Relapse to cocaine- and heroin-seeking behavior mediated by dopamine D2 receptors is time-dependent and associated with behavioral sensitization. Neuropsychopharmacol 26: 18-26. 
Di Ciano P, Everitt BJ (2001). Dissociable effects of antagonism of NMDA and AMPA/KA receptors in the nucleus accumbens core and shell on cocaine-seeking behavior. Neuropsychopharmacol 25: $341-360$.

Famous KR, Kumaresan V, Sadri-Vakili G, Schmidt HD, Mierke DF, Cha JH et al. (2008). Phosphorylation-dependent trafficking of GluR2-containing AMPA receptors in the nucleus accumbens plays a critical role in the reinstatement of cocaine seeking. J Neurosci 28: 11061-11070.

Ferrario CR, Gorny G, Crombag HS, Li Y, Kolb B, Robinson TE (2005). Neural and behavioral plasticity associated with the transition from controlled to escalated cocaine use. Biol Psychiatry 58: 751-759.

Fitzgerald LW, Ortiz J, Hamedani AG, Nestler EJ (1996). Drugs of abuse and stress increase the expression of GluR1 and NMDAR1 glutamate receptor subunits in the rat ventral tegmental area: common adaptations among cross-sensitizing agents. J Neurosci 16: 274-282.

Ghasemzadeh MB, Mueller C, Vasudevan P (2009). Behavioral sensitization to cocaine is associated with increased glutamate receptor trafficking to the postsynaptic density after extended withdrawal period. Neurosci 159: 414-426.

Goto Y, Grace AA (2005). Dopamine-dependent interactions between limbic and prefrontal cortical plasticity in the nucleus accumbens: disruption by cocaine sensitization. Neuron 47: 255-266.

Greger IH, Esteban JA (2007). AMPA receptor biogenesis and trafficking. Curr Opin Neurobiol 17: 289-297.

Groenewegen HJ, Wright CI, Beijer AV, Voorn P (1999). Convergence and segregation of ventral striatal inputs and outputs. Ann NY Acad Sci 877: 49-63.

Holtmaat A, Svoboda K (2009). Experience-dependent structural synaptic plasticity in the mammalian brain. Nat Rev Neurosci 10: 647-658.

Horger BA, Shelton K, Schenk S (1990). Preexposure sensitizes rats to the rewarding effects of cocaine. Pharm Biochem Behav 37: 707-711.

Hu X-T, White FJ (1996). Glutamate receptor regulation of rat nucleus accumbens neurons in vivo. Synapse 23: 208-218.

Huang YH, Lin Y, Mu P, Lee BR, Brown TE, Wayman G et al. (2009). In vivo cocaine experience generates silent synapses. Neuron 63: 40-47.

Jedynak JP, Uslaner JM, Esteban JA, Robinson TE (2007). Methamphetamine-induced structural plasticity in the dorsal striatum. Eur J Neurosci 25: 847-853.

Kelley AE (2004). Ventral striatal control of appetitive motivation: role in ingestive behavior and reward-related learning. Neurosci Biobehav Rev 27: 765-776.

Kim M, Au E, Neve R., Yoon BJ (2009). AMPA receptor trafficking in the dorsal striatum is critical for behavioral sensitization to cocaine in juvenile mice. Biochem Biophys Res Comm 379: 65-69.

Kopec CD, Real E, Kessels HW, Malinow R (2007). GluR1 links structural and functional plasticity at excitatory synapses. J Neurosci 27: 13706-13718.

Kourrich S, Rothwell PE, Klug JR, Thomas MJ (2007). Cocaine experience controls bidirectional synaptic plasticity in the nucleus accumbens. J Neurosci 27: 7921-7928.

Koya E, Golden SA, Harvey BK, Guez-Barber DH, Berkow A, Simmons DE et al. (2009). Targeted disruption of cocaineactivated nucleus accumbens neurons prevents context-specific sensitization. Nat Neurosci 12: 1069-1073.

Lee KW, Kim Y, Kim AM, Helmin K, Nairn AC, Greengard P (2006). Cocaine-induced dendritic spine formation in D1 and D2 dopamine receptor-containing medium spiny neurons in nucleus accumbens. Proc Natl Acad Sci USA 103: 3399-3404.

Lett BT (1989). Repeated exposures intensify rather than diminish the rewarding effects of amphetamine, morphine, and cocaine. Psychopharmacol (Berlin) 98: 357-362.
Li Y, Acerbo MJ, Robinson TE (2004). The induction of behavioural sensitization is associated with cocaine-induced structural plasticity in the core (but not shell) of the nucleus accumbens. Eur J Neurosci 20: 1647-1654.

Loftis JM, Janowsky A (2000). Regulation of NMDA receptor subunits and nitric oxide synthase expression during cocaine withdrawal. J Neurochem 75: 2040-2050.

Lu W, Shi Y, Jackson AC, Bjorgan K, During MJ, Sprengel R et al. (2009). Subunit composition of AMPA receptors revealed by a single-cell genetic approach. Neuron 62: 254-268.

McGeorge AJ, Faull RL (1989). The organization of the projection from cerebral cortex to the striatum in the rat. Neurosci 29: 503-537.

Moghaddam B (1993). Stress preferentially increases extraneuronal levels of excitatory amino acids in the prefrontal cortex: comparison to hippocampus and basal ganglia. J Neurochem 60: $1650-1657$.

Moussawi K, Pacchioni A, Moran M, Olive MF, Gass JT, Lavin A et al. (2009). N-acetylcysteine reverses cocaine-induced metaplasticity. Nat Neurosci 12: 182-189.

Nelson CL, Milovanovic M, Wetter JB, Ford KA, Wolf ME (2009). Behavioral sensitization to amphetamine is not accompanied by changes in glutamate receptor surface expression in the rat nucleus accumbens. J Neurochem 109: 35-51.

Pennartz CMA, Boejinga PH, Lopes da Silva FH (1990). Locally evoked potentials in slices of the rat nucleus accumbens: NMDA and non-NMDA receptor mediated components and modulation by GABA. Brain Res 529: 30-41.

Pierce RC, Bell K, Duffy P, Kalivas PW (1996). Repeated cocaine augments excitatory amino acid transmission in the nucleus accumbens only in rats having developed behavioral sensitization. J Neurosci 16: 1550-1560.

Pierce RC, Kalivas PW (1997). A circuitry model of the expression of behavioral sensitization to amphetamine-like psychostmiulants. Brain Res Rev 25: 192-216.

Ping A, Xi J, Prasad BM, Wang MH, Kruzich PJ (2008). Contributions of nucleus accumbens core and shell GluR1 containing AMPA receptors in AMPA- and cocaine-primed reinstatement of cocaineseeking behavior. Brain Res 1215: 173-182.

Reimers JM, Boudreau AC, Wolf ME (2007). A quantitative analysis of AMPA receptor subunit composition in addictionrelated brain regions. Soc Neurosci Abstr 33: 815-819.

Robinson TE, Kolb B (2004). Structural plasticity associated with exposure to drugs of abuse. Neuropharmacol 47: 33-46.

Safferling M, Tichelaar W, Kümmerle G, Jouppila A, Kuusinen A, Keinänen K et al. (2001). First images of a glutamate receptor ion channel: oligomeric state and molecular dimensions of GluRB homomers. Biochemistry 40: 13948-13953.

Scheggi S, Mangiavacchi S, Masi F, Gambarana C, Tagliamonte A, De Montis MG (2002). Dizocilpine infusion has a different effect in the development of morphine and cocaine sensitization; behavioral and neurochemical aspects. Neurosci 109: 267-274.

Schumann J, Yaka R (2009). Prolonged withdrawal from repeated noncontingent cocaine exposure increases NMDA receptor expression and ERK activity in the nucleus accumbens. J Neurosci 29: 6955-6963.

Shen HW, Toda S, Moussawi K, Bouknight A, Zahm DS, Kalivas PW (2009). Altered dendritic spine plasticity in cocainewithdrawn rats. J Neurosci 29: 2876-2884.

Suto N, Tanabe LM, Austin JD, Creekmore E, Pham CT, Vezina P (2004). Previous exposure to psychostimulants enhances the reinstatement of cocaine seeking by nucleus accumbens AMPA. Neuropsychopharmacol 29: 2149-2159.

Thomas MJ, Beurrier C, Bonci A, Malenka RC (2001). Long-term depression in the nucleus accumbens: a neural correlate of behavioral sensitization to cocaine. Nat Neurosci 4: 1217-1223. 
Todtenkopf MS, Stellar JR, Melloni Jr RH (2002). Neither ibotenic acid nor volkensin lesions of the nucleus accumbens shell affect the expression of cocaine sensitization. Eur J Neurosci 61: 541-546.

Tucker DC, Campioni M, Bubula N, Suto N, McGehee DS, Vezina P (2008). Previous exposure to amphetamine functionally up-regulates nucleus accumbens glutamate transmission without changing basal AMPA receptor surface expression. Soc Neurosci Abstr 34: 358.

Uslaner J, Badiani A, Norton CS, Day HE, Watson SJ, Akil H et al. (2001). Amphetamine and cocaine induce different patterns of c-fos mRNA expression in the striatum and subthalamic nucleus depending on environmental context. Eur J Neurosci 13: 1977-1983.
Vanderschuren LJ, Kalivas PW (2000). Alterations in dopaminergic and glutamatergic transmission in the induction and expression of behavioral sensitization: a critical review of preclinical studies. Psychopharm (Berl) 151: 99-120.

Vezina P (2004). Sensitization of midbrain dopamine neuron reactivity and the self-administration of psychomotor stimulant drugs. Neurosci Biobehav Rev 27: 827-839.

Wolf ME (2002). Effects of psychomotor stimulants on glutamate receptor expression.. In: Wang JQ (ed) Methods in Molecular Medicine vol. 79 Drugs of Abuse: Analysis of Neurological Effect. Humana Press: Totowa, New Jersey. pp 13-31.

Yao WD, Gainetdinov RR, Arbuckle MI, Sotnikova TD, Cyr M, Beaulieu JM et al. (2004). Identification of PSD-95 as a regulator of dopaminemediated synaptic and behavioral plasticity. Neuron 41: 625-638.

Supplementary Information accompanies the paper on the Neuropsychopharmacology website (http://www.nature.com/npp) 